\title{
Application of multiple analysis methods in optimising complex residual stress characterisation
}

\author{
S. Hossain ${ }^{1,2}$ (1) - G. Zheng ${ }^{1,3}$ - C.E. Truman ${ }^{1}$ - D.J. Smith ${ }^{1}$
}

Received: 10 January 2017 / Accepted: 13 June 2017 / Published online: 12 July 2017

(C) The Author(s) 2017. This article is an open access publication

\begin{abstract}
An accurate characterisation of residual stress plays an important role in the structural integrity assessment of an engineering component. Several techniques and tools are available for measuring and predicting residual stresses. For example, neutron diffraction (ND) and X-ray diffraction (XRD) are non-destructive techniques used for measuring through-thickness and surface residual stresses respectively, while the deep-hole drilling (DHD) and the incremental centre-hole drilling (ICHD) are semi-destructive techniques and measure through-thickness and sub-surface residual stress respectively. In most open literature, a more favoured method is traditionally used over others, with some degree of validation using finite element analysis (FEA) predictive tool. In this paper it will be shown that the different methods and tools available are not contradicting or more superior to the others, but rather, the use of more than one available technique complementary to each other can improve the quality and the confidence in the characterisation of the residual stress state in an engineering component. In particular, the accurate knowledge of the residual stress field for a safety critical
\end{abstract}

In memory of Prof. David Smith (1952-2015) who sadly passed away on 13 November 2015

\section{S. Hossain}

S.Hossain@bristol.ac.uk; Sayeed.Hossain@mtc.edu.om

1 Department of Mechanical Engineering, University of Bristol, Bristol BS8 1TR, UK

2 Department of Aeronautical Engineering, Military Technological College, Muscat, Sultanate of Oman

3 State Power Investment Corporation Central Research Institute, South Park of Beijing Future Science \& Technology Park, Chang Ping District, Beijing 102209, China component plays a vital role for subsequent structural integrity assessment.

Keywords Residual stress $\cdot$ neutron diffraction $\cdot$ conventional and modified deep-hole drilling · finite element simulation . quenching $\cdot$ autogenous welding

\section{Introduction}

Residual stresses can arise in engineering components in a number of different ways. Manufacturing process such as the heat treatment process to impart beneficial material properties is a common means of introducing residual stresses into the components. With further manipulation of components, e.g. manufacturing to final designed parts the residual stresses can redistribute in a non-linear and unpredictable manner. The stress redistribution can give rise to part distortions which may be too significant to ignore. Subsequent correction of these part distortions in aluminium alloys can cost aircraft industry in excess of millions of Euros per annum. In order to gain an understanding of the relationship between the stress redistribution during machining and the part distortion in the final machined parts, an accurate characterisation of the original residual stress distribution is a pre-requisite.

Several residual stress measurement techniques are available in open literature. Measurements of residual stresses may be carried out using non-destructive techniques such as the Xray diffraction (XRD) and the neutron diffraction (ND) or using semi-destructive techniques such as the incremental centre-hole drilling (ICHD) and the deep-hole drilling (DHD) technique. The XRD and ICHD measurements are limited to the near surface whereas the ND and DHD can measure well into the depth of components. The ND technique is not readily available and is not portable. Although 
the ND technique suffers from its penetrative depth limit of about $30 \mathrm{~mm}$ corresponding to $60 \mathrm{~mm}$ sample thickness in most steels [1], the penetration is not an issue in aluminium alloys. However, the presence of strong texture in aluminium alloys can complicate the data interpretation in the ND measurement by prohibiting measurements of certain hkl reflections in certain directions [2].

In contrast, the DHD technique is portable and can measure residual stresses in components as thick as $800 \mathrm{~mm}$ [3]. Like all other mechanical strain relief techniques, the DHD technique works by measuring distortions (diametral distortions) when part of the component is machined away. The underlying assumption is that such displacement changes result from elastic unloading. Furthermore, unlike in the ND technique where good result depends on an accurate design of a stressfree reference sample, the DHD technique is robust and does not have a stress-free reference sample issue. However, in components containing high levels of residual stresses, elastic-plastic unloading may well occur, particularly when the residual stresses are highly triaxial, for example, for quenched or welded components. A modification is made to the existing conventional DHD procedure which accounts for the additional change in diametral distortions during the elastic-plastic unloading steps. A finite element model of the DHD procedure is also constructed in parallel. The simulation forms an important guide for carrying out the practical measurements.

In order to illustrate how using the finite element analysis, the neutron diffraction and the deep-hole drilling (both the conventional and the modified DHD) measurement techniques in a constructive manner to achieve an optimised solution, three specimens were considered in the present study. These included (i) water quenched forged rectilinear block specimen manufactured from 7449 aluminium alloy, (ii) a stainless steel circular disc containing a partial ring weld (RW) manufactured from an Esshete material and (iii) an autogenously welded "bead-on-plate" rectangular plate specimen manufactured from stainless steel. These specimens produce highly triaxial stress states and were therefore suitable for the present study. The test specimens and materials are described in the next section followed by description of the finite element analyses and measurement results. Finally results are discussed with a view of optimising the several residual stress characterisation techniques including the FEA tool in order to achieve an optimum solution.

\section{Test Specimen and Material Description}

\section{Quenched Forged Block}

Figure 1(a) shows the schematic of a cold water quenched rectilinear forged block manufactured from 7449 aluminium alloy with dimension L430 $\times$ LT156 $\times \mathrm{ST} 123 \mathrm{~mm}^{3}$, where L is the longitudinal length, LT the long transverse length and ST the short transverse length. Detail of the forging process can be found in [4]. The forged block was solution heat treated at $470 \pm 5{ }^{\circ} \mathrm{C}$ for $5 \mathrm{~h}$ followed by immersion quenching into agitated water at less than $20^{\circ} \mathrm{C}$. Red arrows shown in Fig. 1 (a) are the residual stress measurement paths using neutron diffraction technique described later. The finite element model mesh shown in Fig. 1(b) is described in Section 3.

\section{Ring Welded Specimen}

The ring welded (RW) specimen consisted of a circular disc containing a recessed multi-pass ring-weld that introduced complex residual stresses of high intensity. Figure 2 shows the schematic and various steps in preparation of the ring welded specimen.

(a) An Esshete 1250 cylindrical bar of diameter $185 \mathrm{~mm}$, thickness $52 \mathrm{~mm}$ shown in Fig. 2(a) was solution heat treated at $1080{ }^{\circ} \mathrm{C}$ for half hour followed by water quenching.

(b) Following water quenching the disc was machined to the final weld groove preparation dimension. As shown in Fig. 2(b), material was removed circumferentially from the disc to a final diameter of $160 \mathrm{~mm}$. The disc was machined equally from both sides to a final circular disc with an overall thickness of $35 \mathrm{~mm}$, and further machined to final weld preparation.

(c) Manual Metal Arc Welding (MMA) was adopted to fill the groove. Welding was carried out in the flat position, according to DIN EN ISO 6947 with the specimen supported, but not restrained. All seven weld passes were deposited in one direction but with different start/stop positions. Figure 2(c) shows the detail of the weld passes.

(d) Figure 3(d) shows the final dimension of the ring weld after welding and final machining. Due to excessive welding distortion, the outer edge of the recess was machined to a depth of $5 \mathrm{~mm}$, while only $4 \mathrm{~mm}$ was machined from the inner edge of the recess. The weld was machined flat.

Figure 2(e) illustrating the finite element modelling is described in detail in Section 3.

\section{Autogenously Welded Plate}

Figure 3(a) shows the schematic of an autogenously welded stainless steel bead-on-plate with dimensions in $\mathrm{mm}$. The finite element half models shown in Fig. 3(b) and (c) are described later in Section 3. The specimen was manufactured from an annealed heat treated AISI type $316 \mathrm{~L}$ stainless steel 
Fig. 1 Schematic and quarter FEA models of the water quenched 7449 aluminium alloy forged block

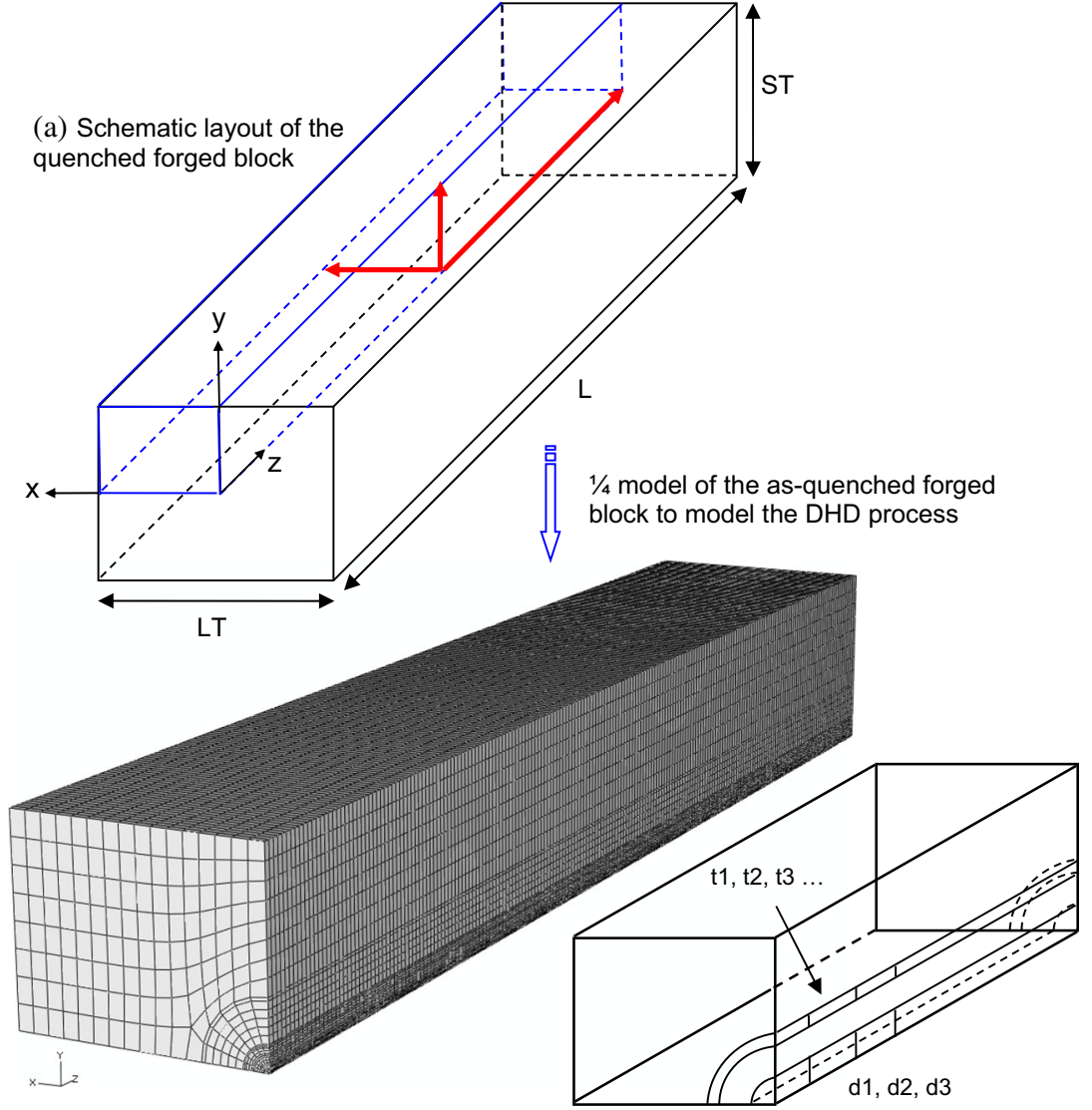

(b) Quarter FE model mesh

(c) Schematic illustrating drilling and trepanning steps block. The plate was of dimension $120 \times 180 \times 20 \mathrm{~mm}^{3}$ and was solution heat treated to eliminate machining and fabrication residual after cutting and machining to ensure minimal residual stresses were present prior to the welding process. The welds were positioned at the centre of the plate width as shown Fig. 3(a). Welding was carried out using argon shrouded TIG arc. As autogenous welding was employed no filler material was used. Further detail of the welding can be found in [5]. The specimen was unrestrained during the welding process to allow any deformation to occur unhindered.

\section{Material Properties}

Table 1 provides the temperature dependent thermal properties [6] including specific heat capacity, thermal conductivity and density for 7449 aluminium alloy. Figure 4 shows the experimentally measured [6] temperature dependent thermal heat transfer coefficient. Also present is the measurement based average value. The temperature dependent mechanical properties including the Young's modulus and the yield stress for 7449 aluminium alloy are shown in Fig. 5.

Table 2 provides the temperature dependent thermal and mechanical properties for $316 \mathrm{~L}$ stainless steel including the conductivity, specific heat capacity, thermal heat expansion and Young's modulus [7, 8]. The temperature dependent yield (proof) stress for $316 \mathrm{~L}$ stainless steel is shown in Fig. 6.

Table 3 provides the temperature dependent thermal and mechanical properties of Esshete 1250 weld and parent stainless steel [9]. The density, conductivity, specific heat, heat transfer coefficient, thermal expansion, Young's modulus, Poisson's ratio, yield stress are all provided as a function of temperature. The physical and mechanical properties are respectively shown in Figs. 7 and 8.

\section{Finite Element Model}

\section{Quenching Model}

The initial residual stress state in the forged block and the quenching step in the ring-weld (RW) preparation shown in Fig. 2(a) were achieved by solving respective non-linear quenching models. The analysis in each case consisted of an uncoupled heat transfer analysis with a subsequent thermal non-linear stress analysis using an isotropic hardening model. The boundary condition included convective heat transfer on the outer surfaces with a heat transfer coefficient of $7000 \mathrm{~W}$ 


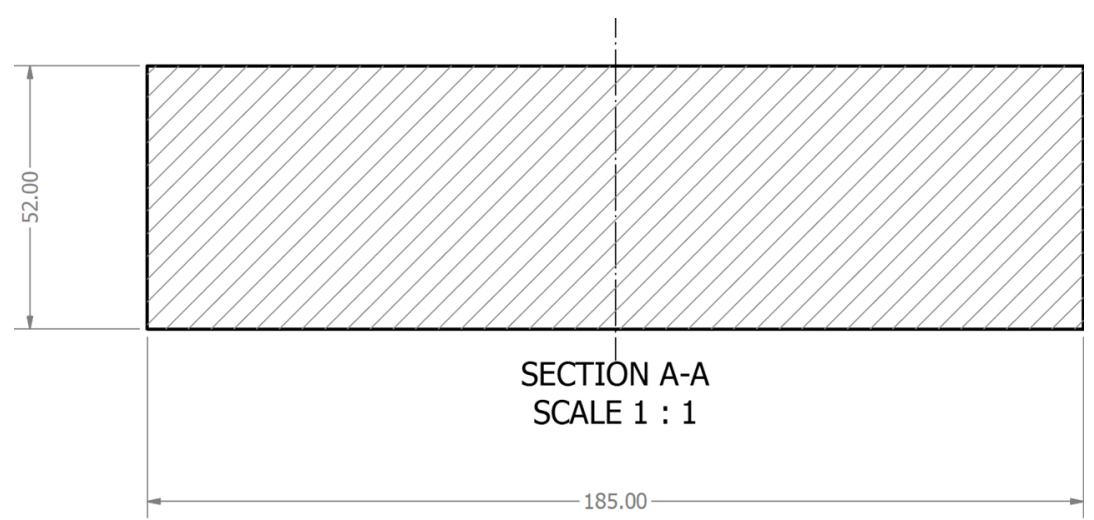

(a) Quenching

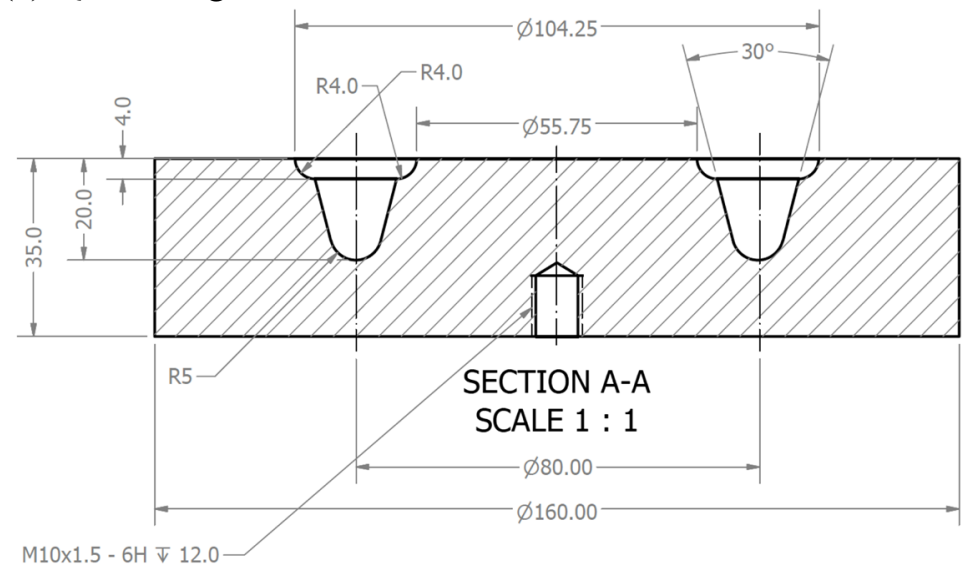

(b) Machine after quenching

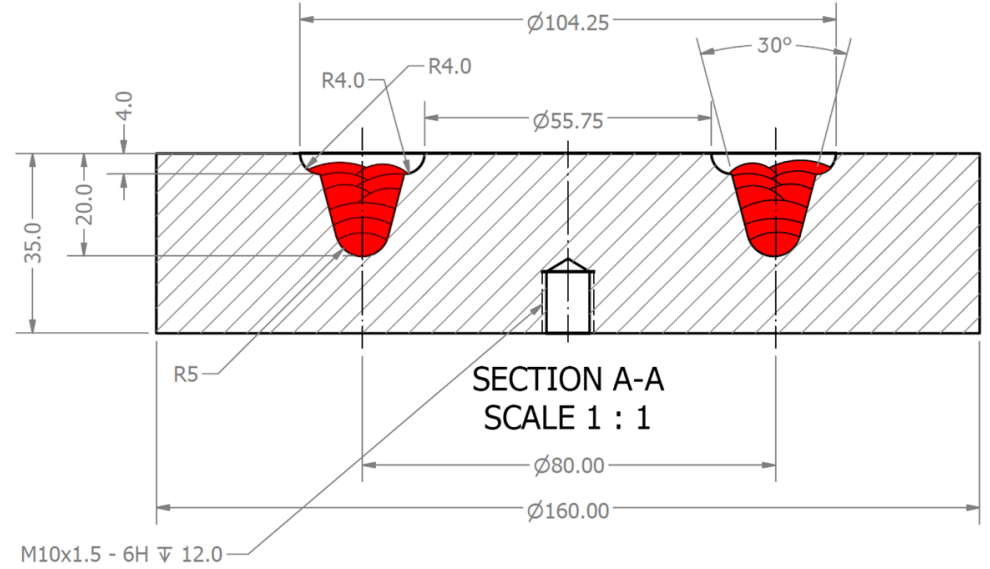

(c) Welding

Fig. 2 Ring welded specimen lifecycle

$m^{-2} K^{-1}$ for the forged block sample and $16,742 \mathrm{~W} \mathrm{~m}^{-2} K^{-1}$ [10] for the quenching of the RW, and an adiabatic condition on symmetry boundaries. The material was assumed elastic with strain hardening plasticity and with a yield stress that decreased with temperature (Figs. 5, 6 and 8).

Figure 1(b) shows the model of the forged block. A quarter model was meshed with 52,800 eight-noded reduced integration brick elements (DC3D8 for the heat transfer analysis and C3D8R for the thermal stress analysis). Although three geometric symmetries existed in the block, a quarter model was used because the third symmetry was not applicable in the deep-hole drilling measurement simulation which occurs from one face to the other. This is further explained in Section 3.3.

Figure 2(e) shows the various stages of the FEA model of the ring weld (RW). A 2D axisymmetric model of the quenching bar was created in stage 1 using 1592 linear quadrilateral elements of type DCAX4 for the heat transfer analysis and CAX4R for the subsequent thermal stress analysis. 


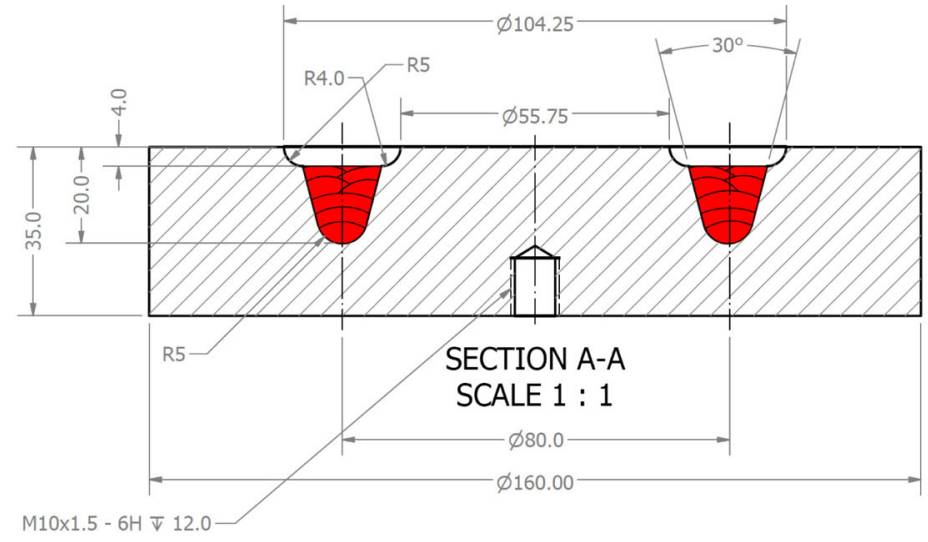

(d) Final machine after welding

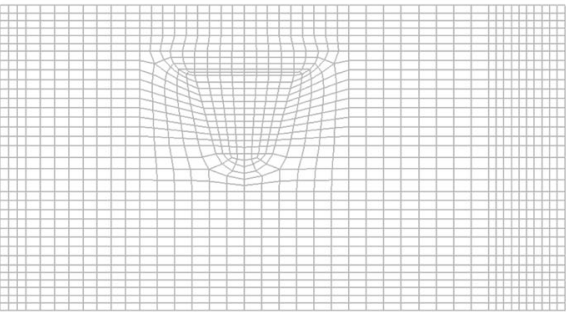

Stage 1 Quenching

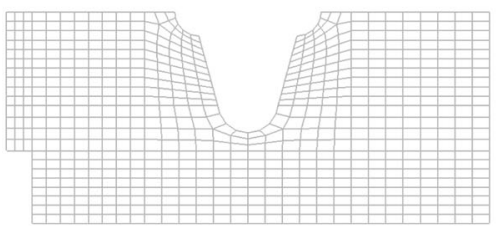

Stage 2(i) After machining stages (a-e)

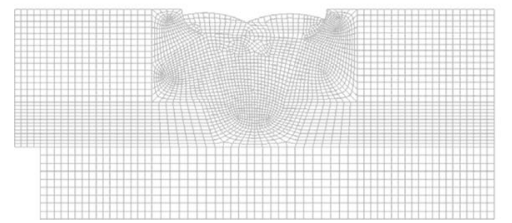

Stage 3(i) After welding with 7 passes

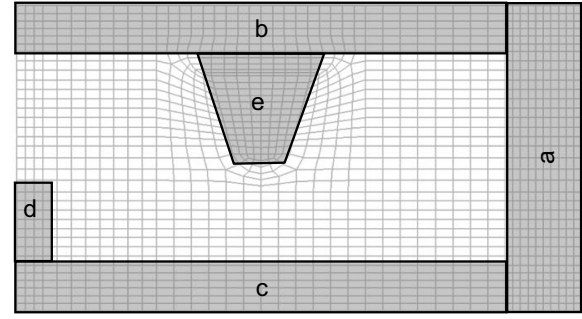

Stage 2 Machining stages (a-e)

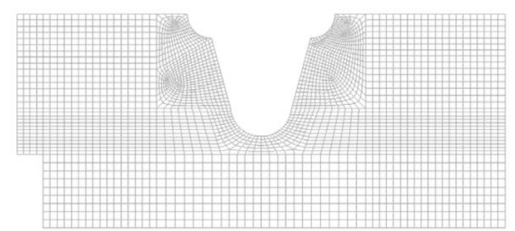

Stage 3 Stress/strain mapped from stage $2 \mathrm{i}$ onto new weld model

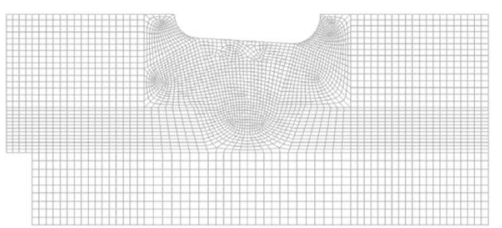

Stage 4 After final machining

(e) FEA modelling procedures for quench/weld and mapping (all in 2D axisymmetric)

Fig. 2 (continued)

Different parts were defined in stage 2. Parts ' $a$ ' to 'e' were machined away during the mechanical analysis. Further details are provided in $[9,11]$. Machining was simulated to reduce the disc thickness to $35 \mathrm{~mm}$ and introduce a weld excavation as illustrated in Fig. 2(e) stage 2(i). The quenching residual stress/strain from Stage 2(i) were both mapped onto the model mesh in stage 3. Note, the effect of phase transformation on residual stress was not deemed important for the austenitic stainless steel material. The quenching residual stress remaining in the welding preparation model was thereby obtained.
The forged block was initially assumed to be at a uniform temperature of $550{ }^{\circ} \mathrm{C}$ and the ring weld at $1080{ }^{\circ} \mathrm{C}$. The specimens were each assumed in a stress-free state. The forged block and the RW specimens were then quenched in water until the entire specimens reached the equilibrium quenchant temperature of $20^{\circ}$ and $100{ }^{\circ} \mathrm{C}$ respectively. During the heat transfer analysis the temperature distributions were stored in the ABAQUS results file. This temperaturetime history was then used as an input loading condition in the thermal stress analysis step. The transient stresses were large enough to cause significant plastic flow, so residual 


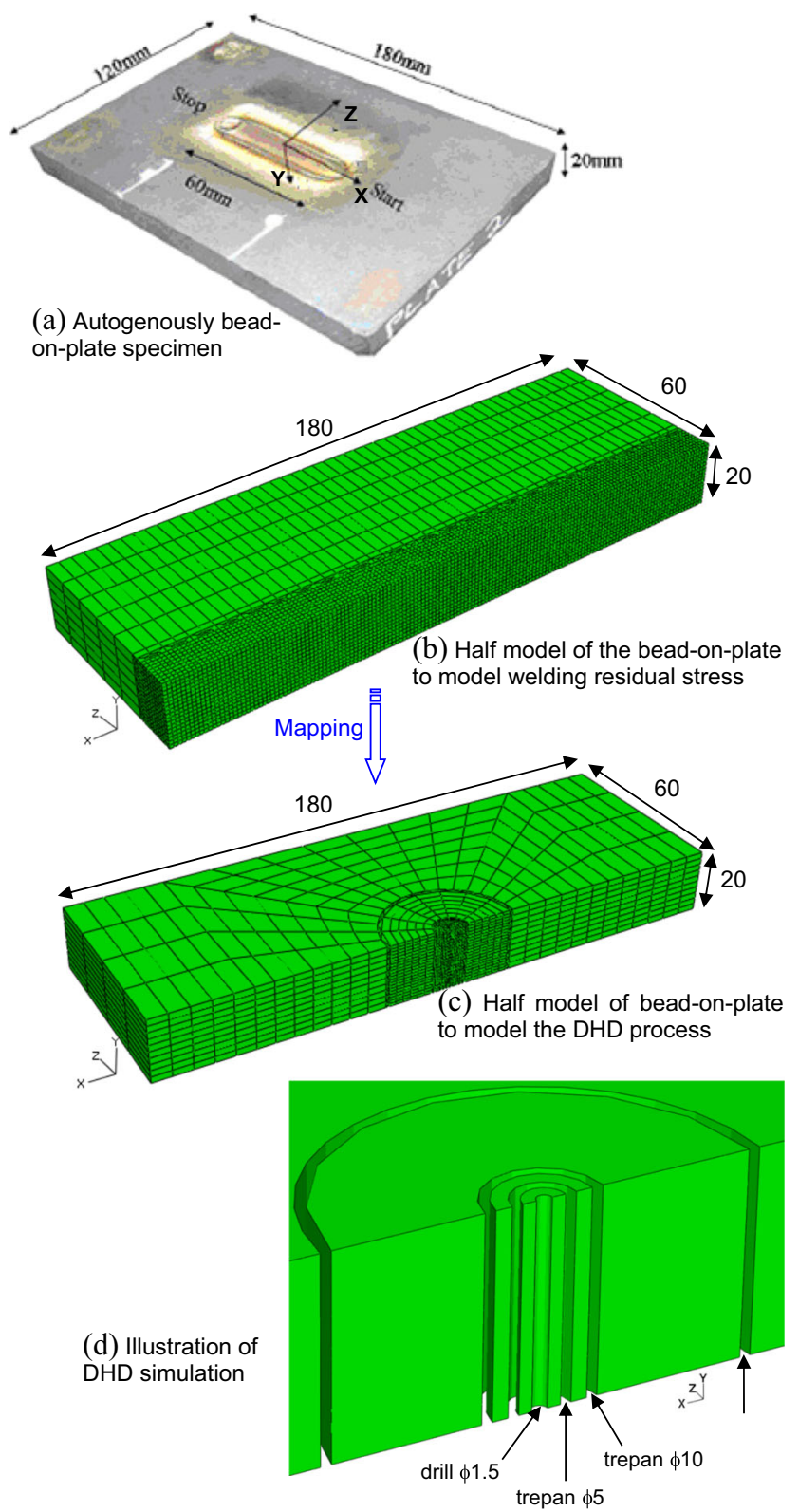

Fig. 3 Autogenously welded bead-on-plate half model to simulate DHD process

Table 1 Temperature dependent thermal properties for 7449 aluminium alloy

\begin{tabular}{llll}
\hline $\begin{array}{l}\text { Temp } \\
\left({ }^{\circ} \mathrm{C}\right)\end{array}$ & $\begin{array}{l}\text { Conductivity }(\mathrm{W} \\
\left.\mathrm{m}^{-1} \mathrm{~K}^{-1}\right)\end{array}$ & $\begin{array}{l}\text { Specific Heat } \\
\left(\mathrm{Jkg}^{-1} \mathrm{~K}^{-1}\right)\end{array}$ & $\begin{array}{l}\text { Density }(\mathrm{kg} \\
\left.\mathrm{m}^{-3}\right)\end{array}$ \\
\hline 20 & 166 & 842 & 2796 \\
93 & 175 & 900 & 2781 \\
205 & 180 & 963 & 2759 \\
316 & 175 & 1055 & 2737 \\
427 & 163 & 1172 & 2715 \\
475 & 156 & 1230 & 2705 \\
\hline
\end{tabular}

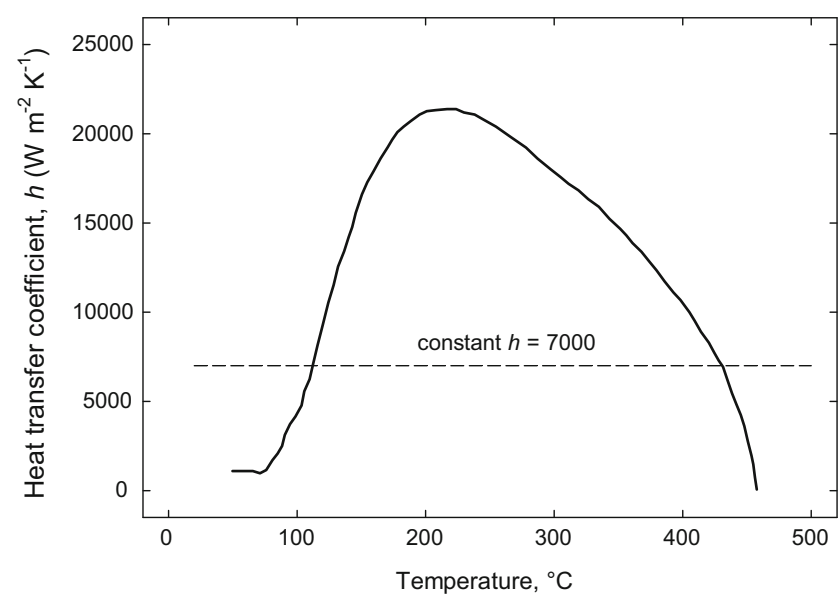

Fig. 4 Experimentally determined [6] temperature dependent thermal heat transfer coefficient for 7449 aluminium alloy and an average constant heat transfer coefficient

stresses remained after the specimens reached the coolant temperature. The effect of phase transformation on residual stress and distortion was considered unimportant.

\section{Welding Model}

\section{Ring weld specimen}

An axisymmetric block-dumped finite element analysis was used to simulate the welding process and predict the residual stress field in the ring weld specimen, Fig. 2(e). Each weld pass was deposited instantaneously as a full ring weld. In order to simplify the model each weld pass consisted of 2-3 weld beads, and each weld pass was assumed only to have one weld bead in the model. The welding model contained seven weld passes, stage 3(i) and a final cap machining line, stage 4 was created.

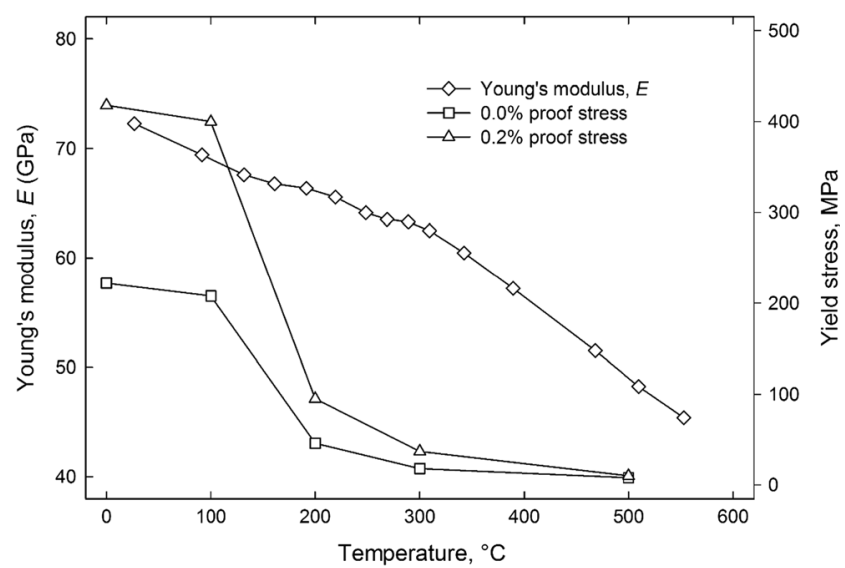

Fig. 5 Temperature dependent Young's modulus and yield stress for 7449 aluminium alloy 
Table 2 Temperature dependent thermal and mechanical properties for $316 \mathrm{~L}$ stainless steel alloy

\begin{tabular}{lllll}
\hline $\begin{array}{l}\text { Temp } \\
\left({ }^{\circ} \mathrm{C}\right)\end{array}$ & $\begin{array}{l}\text { Conductivity } \\
\left(\mathrm{W} \mathrm{m}^{-1} \mathrm{~K}^{-1}\right)\end{array}$ & $\begin{array}{l}\text { Specific Heat } \\
\left(\mathrm{Jkg}^{-1} \mathrm{~K}^{-1}\right)\end{array}$ & $\begin{array}{l}\text { Expansion coeff } \\
\left(1 \times 10^{-6} \mathrm{~K}^{-1}\right)\end{array}$ & $\begin{array}{l}\text { Young's } \\
\text { modulus, } \\
\mathrm{GPa}\end{array}$ \\
\hline 20 & 14.12 & 492 & 14.6 & 196 \\
100 & 15.26 & 502 & 15.4 & 191 \\
200 & 16.69 & 514 & 16.2 & 186 \\
300 & 18.11 & 526 & 16.9 & 180 \\
400 & 19.54 & 538 & 17.4 & 173 \\
500 & 20.96 & 550 & 17.8 & 165 \\
600 & 22.38 & 562 & 18.1 & 155 \\
700 & 23.81 & 575 & 18.4 & 144 \\
800 & 25.23 & 587 & 18.7 & 131 \\
900 & 26.66 & 599 & 19 & 117 \\
1000 & 28.08 & 611 & 19.3 & 100 \\
1100 & 29.5 & 623 & 19.5 & 80 \\
1200 & 30.93 & 635 & 19.8 & 57 \\
1300 & 32.35 & 647 & 20 & 30 \\
1400 & 33.78 & 659 & 20.2 & 2 \\
\hline
\end{tabular}

The mesh employed for the thermal analysis consisted of 3952 linear quadrilateral elements of type DCAX4 (4-node linear axisymmetric heat transfer quadrilateral). The welding and adjacent regions were meshed with refined element sizes as shown in Fig. 2(e). Thermal boundary conditions of convective heat transfer coefficients were applied to the model. The top surface had temperature dependent coefficients ranging from $4.2 \mathrm{Wm}^{-2} \mathrm{~K}^{-1}$ at $20{ }^{\circ} \mathrm{C}$ to $13.21 \mathrm{Wm}^{-2} \mathrm{~K}^{-1}$ at $1400{ }^{\circ} \mathrm{C}[9,11]$. Fixed convective heat transfer coefficients, $7 \mathrm{Wm}^{-2} \mathrm{~K}^{-1}$ for the side and $3 \mathrm{Wm}^{-2} \mathrm{~K}^{-1}$ for the bottom were applied to the model. The model consisted of 7 weld passes. The weld beads, yet to be deposited, should be physically isolated from the rest of the model. This was achieved by

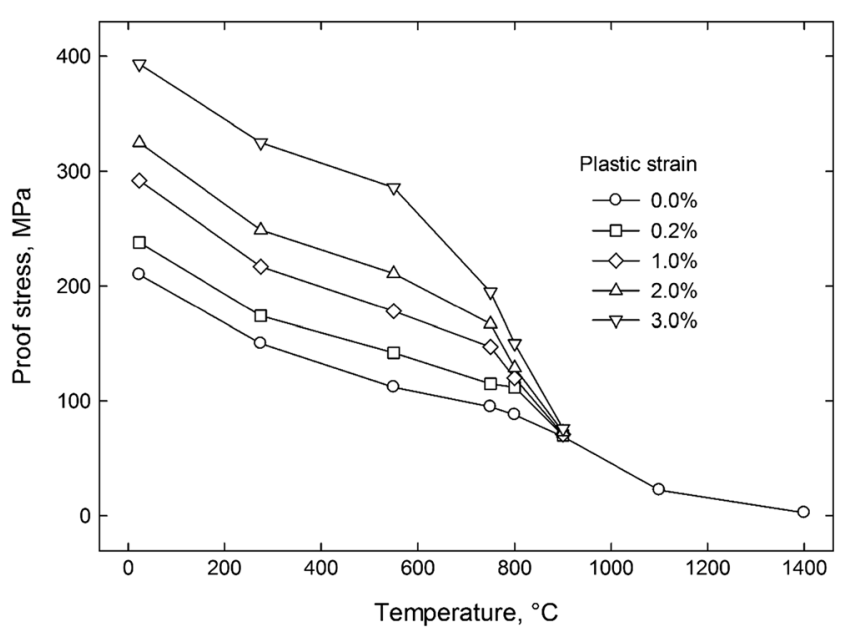

Fig. 6 Temperature dependent yield stress for $316 \mathrm{~L}$ stainless steel [7, 8] initially removing all the element sets for the 7 weld passes and then activating relevant weld pass element sets as required.

A thermal model was initialised at room temperature with all the weld beads removed. A simple heat source model was adapted to simulate the welding process using the following steps, (1) the weld bead into the FEA model at a fixed temperature of $1400{ }^{\circ} \mathrm{C}$ was introduced and the deposited bead held at this temperature for an arbitrary period, (2) a heat flux for a period of time was applied to simulate the weld torch, (3) the specimen allowed to cool down. The heat input to each weld bead consisted of holding for a period at the molten temperature and with a heat flux. The heat flux was directly determined from the recorded welding details provided in [9, 11], i.e. heat input, advance rate, weld pass cross section area, pass length, weld efficiency. These five parameters determine the 'Reduced Body Flux' value. The final step was to remove all the input heat source and cool the specimen down to room temperature of $20^{\circ} \mathrm{C}$.

The welding thermal model consisted of 3592 linear quadrilateral elements of type CAX4 (4-node bilinear axisymmetric quadrilateral). The quenching residual stress was mapped onto this model before the welding mechanical analysis was conducted. The only loads imposed on the welding model were transient thermal loads calculated from the previous thermal analysis.

Final machining was later conducted to machine flat the weld top as shown in Fig. 2(e). The machined parts were individually partitioned and assigned an element set in ABAQUS CAE and machining was achieved by using the '*MODEL CHANGE, REMOVE' ABAQUS keyword, the same procedure as in the quench machining. The effect of phase transformation on residual stress was not considered important for the austenitic stainless steel material. The residual stress remaining in the ring weld model was thus obtained.

\section{Autogenously welded plate}

The welding simulation consisted of a thermal analysis to calculate the nodal temperature produced by a moving heat source and a mechanical analysis to predict the expansions and residual stresses in the model [5]. As the welding was carried out on a straight line in the middle of the plate as shown in Fig. 3(a), the weld line formed a symmetry line in the middle of the plate and consequently half of the plate was modelled. The welding model shown in Fig. 3(b) was meshed by using 27,232 linear 8-noded reduced integration brick elements (C3D8R) for the mechanical analysis and fully integrated heat transfer elements (DC3D8) for the thermal analysis [5]. The thermal analysis was carried out using ABAQUS version 6.6 finite element code [12]. 
Table 3 Temperature dependent thermal and mechanical properties Esshete 1250 stainless steel alloy for both weld and parent.

\begin{tabular}{|c|c|c|c|c|c|c|c|c|}
\hline Temp. & Density & Conductivity & Specific Heat & Film property & $\begin{array}{l}\text { Thermal } \\
\text { Expansion }\end{array}$ & $\begin{array}{l}\text { Parent Young's } \\
\text { Modulus }\end{array}$ & $\begin{array}{l}\text { Weld Young's } \\
\text { Modulus }\end{array}$ & Posson's Ratio \\
\hline${ }^{\circ} \mathrm{C}$ & $\mathrm{Kg} / \mathrm{m} 3$ & $\mathrm{~W} / \mathrm{m} * \mathrm{~K}$ & $\mathrm{~J} / \mathrm{Kg}^{*} \mathrm{~K}$ & $\mathrm{~W} / \mathrm{m} 2 * \mathrm{~K}$ & $\mathrm{~m} / \mathrm{m} * \mathrm{~K}$ & $\mathrm{~Pa}$ & $\mathrm{~Pa}$ & \\
\hline 20 & 7960 & 12.69 & 490 & 4.15 & $1.54 \mathrm{E}-05$ & $2.05 \mathrm{E}+11$ & $1.72 \mathrm{E}+11$ & 0.294 \\
\hline 100 & 7930 & 13.93 & 508 & 5.03 & $1.60 \mathrm{E}-05$ & $1.97 \mathrm{E}+11$ & $1.65 \mathrm{E}+11$ & 0.294 \\
\hline 200 & 7890 & 15.48 & 532 & 5.99 & $1.67 \mathrm{E}-05$ & $1.88 \mathrm{E}+11$ & $1.57 \mathrm{E}+11$ & 0.294 \\
\hline 300 & 7850 & 17.03 & 555 & 6.70 & $1.73 \mathrm{E}-05$ & $1.80 \mathrm{E}+11$ & $1.50 \mathrm{E}+11$ & 0.294 \\
\hline 400 & 7810 & 18.58 & 580 & 7.46 & $1.79 \mathrm{E}-05$ & $1.73 \mathrm{E}+11$ & $1.43 \mathrm{E}+11$ & 0.294 \\
\hline 500 & 7770 & 20.13 & 603 & 8.22 & $1.84 \mathrm{E}-05$ & $1.65 \mathrm{E}+11$ & $1.36 \mathrm{E}+11$ & 0.294 \\
\hline 600 & 7730 & 21.68 & 627 & 9.06 & $1.89 \mathrm{E}-05$ & $1.56 \mathrm{E}+11$ & $1.28 \mathrm{E}+11$ & 0.294 \\
\hline 700 & 7680 & 23.23 & 650 & 9.78 & $1.94 \mathrm{E}-05$ & $1.46 \mathrm{E}+11$ & $1.19 \mathrm{E}+11$ & 0.294 \\
\hline 800 & 7640 & 24.78 & 650 & 10.53 & $1.98 \mathrm{E}-05$ & $1.35 \mathrm{E}+11$ & $1.09 \mathrm{E}+11$ & 0.294 \\
\hline 900 & 7600 & 26.33 & 650 & 11.33 & $2.02 \mathrm{E}-05$ & $1.21 \mathrm{E}+11$ & $9.77 \mathrm{E}+10$ & 0.294 \\
\hline 1000 & 7550 & 27.88 & 650 & 11.77 & $2.05 \mathrm{E}-05$ & $1.04 \mathrm{E}+11$ & $8.41 E+10$ & 0.294 \\
\hline 1100 & 7550 & 29.43 & 650 & 12.21 & $2.08 \mathrm{E}-05$ & $8.48 \mathrm{E}+10$ & $6.80 \mathrm{E}+10$ & 0.294 \\
\hline 1200 & 7550 & 30.98 & 650 & 12.57 & $2.10 \mathrm{E}-05$ & $6.15 E+10$ & $4.92 \mathrm{E}+10$ & 0.294 \\
\hline 1300 & 7550 & 32.53 & 650 & 12.89 & $2.12 \mathrm{E}-05$ & $3.41 \mathrm{E}+10$ & $2.72 \mathrm{E}+10$ & 0.294 \\
\hline 1400 & 7550 & 34.08 & 650 & 13.21 & $2.14 \mathrm{E}-05$ & $2.00 \mathrm{E}+09$ & $1.70 \mathrm{E}+09$ & 0.294 \\
\hline \multirow[t]{2}{*}{ Temp. } & Parent & & & & & & Weld & \\
\hline & $\begin{array}{l}0 \% \text { Plastic } \\
\text { Strain }\end{array}$ & $\begin{array}{l}0.2 \% \text { Plastic } \\
\text { Strain }\end{array}$ & $\begin{array}{l}1 \% \text { Plastic } \\
\text { Strain }\end{array}$ & $\begin{array}{l}1.98 \% \text { Plastic } \\
\text { Strain }\end{array}$ & $\begin{array}{l}4.88 \% \text { Plastic } \\
\text { Strain }\end{array}$ & $10 \%$ Plastic Strain & $0 \%$ Plastic Strain & $\begin{array}{l}10 \% \text { Plastic } \\
\text { Strain }\end{array}$ \\
\hline${ }^{\circ} \mathrm{C}$ & $\mathrm{Pa}$ & $\mathrm{Pa}$ & $\mathrm{Pa}$ & $\mathrm{Pa}$ & $\mathrm{Pa}$ & $\mathrm{Pa}$ & $\mathrm{Pa}$ & $\mathrm{Pa}$ \\
\hline 20 & $3.08 \mathrm{E}+08$ & $3.24 \mathrm{E}+08$ & $3.87 \mathrm{E}+08$ & $4.16 \mathrm{E}+08$ & $4.75 E+08$ & $5.29 \mathrm{E}+08$ & $5.29 \mathrm{E}+08$ & $5.32 \mathrm{E}+08$ \\
\hline 250 & $2.28 \mathrm{E}+08$ & $2.41 E+08$ & $2.90 \mathrm{E}+08$ & $3.16 \mathrm{E}+08$ & $3.75 \mathrm{E}+08$ & $4.70 \mathrm{E}+08$ & $4.70 \mathrm{E}+08$ & $4.72 \mathrm{E}+08$ \\
\hline 500 & $1.93 E+08$ & $2.04 \mathrm{E}+08$ & $2.51 \mathrm{E}+08$ & $2.76 \mathrm{E}+08$ & $3.43 \mathrm{E}+08$ & $4.15 \mathrm{E}+08$ & $4.15 E+08$ & $4.17 \mathrm{E}+08$ \\
\hline 600 & $1.94 \mathrm{E}+08$ & $2.05 \mathrm{E}+08$ & $2.50 \mathrm{E}+08$ & $2.77 \mathrm{E}+08$ & $3.40 \mathrm{E}+08$ & $3.82 \mathrm{E}+08$ & $3.82 \mathrm{E}+08$ & $3.84 \mathrm{E}+08$ \\
\hline 750 & $1.64 \mathrm{E}+08$ & $1.70 \mathrm{E}+08$ & $1.95 \mathrm{E}+08$ & $2.10 \mathrm{E}+08$ & $2.34 \mathrm{E}+08$ & $2.51 \mathrm{E}+08$ & $3.05 \mathrm{E}+08$ & $3.07 \mathrm{E}+08$ \\
\hline 900 & $8.70 \mathrm{E}+07$ & & & & & $8.74 \mathrm{E}+07$ & $1.59 \mathrm{E}+08$ & $1.60 \mathrm{E}+08$ \\
\hline 1100 & $3.80 \mathrm{E}+07$ & & & & & $3.82 \mathrm{E}+07$ & $5.30 \mathrm{E}+07$ & $5.33 \mathrm{E}+07$ \\
\hline 1400 & $3.80 \mathrm{E}+06$ & & & & & $3.80 \mathrm{E}+06$ & $5.30 \mathrm{E}+06$ & $5.30 \mathrm{E}+06$ \\
\hline
\end{tabular}

The autogenous bead on plate was simulated using a moving heat source representing the welding torch on the surface of the plate. The heat source also moved along the weld bead at the advance rate measured during welding of the test specimen. Moving heat source was simulated using user-defined subroutine (DFLUX) in the ABAQUS finite element code [12]. A surface heat flux was used to heat up the surface of the

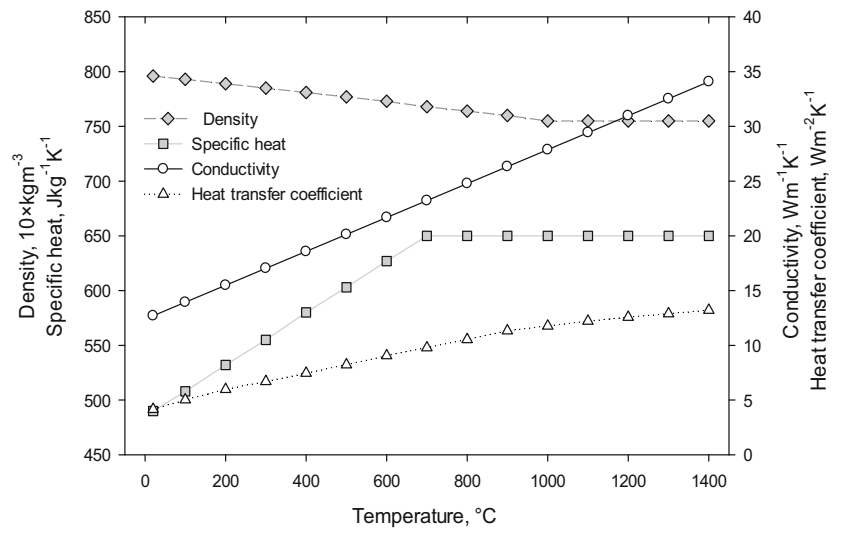

Fig. 7 Esshete 1250 stainless steel physical properties

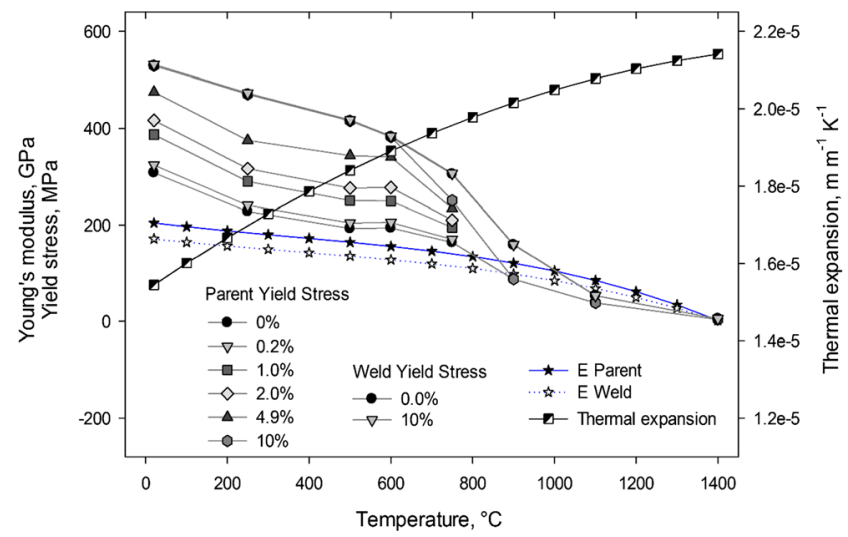

Fig. 8 Esshete 1250 stainless steel mechanical properties 
bead path. The parameters in the thermal analysis were obtained on an iteration basis by changing their values in Rosenthal analytical thermal solution for a moving heat source [13] and the finite element thermal analysis of a moving heat source on a plate until the predicted nodal temperature history closely matched the thermocouple measured temperature history. Thermal boundary conditions were defined as convection from all the exterior surfaces. The radiation heat transfer was ignored and overall heat loss was considered in convective heat lost from free surfaces.

The mechanical modelling of weld simulations was carried out using ABAQUS 6.6. The only load imposed on the mechanical model was transient thermal loads that were defined via the nodal temperature data calculated by the thermal analysis. Plastic strain annealing was used to remove the high temperature plastic strains that accumulate at temperature above the molten temperature. This assumption has a physical basis that when the material exceeds its molten temperature (becomes fluid) the plastic strain history is removed. The plastic strain is introduced when the re-solidification occurs. With no plastic strain annealing the plastic strains developed in the temperature above the melting point of the material, when the metal is fluid, will be included in the total stress and strain calculations. In order to have more realistic simulation of welding the annealing temperature of $1400{ }^{\circ} \mathrm{C}$ was also introduced into the model. Only the mechanical part of the model was constrained to prevent the plate from rigid body motion; the plate was free to deform in all directions as the specimen was not constrained during welding process.

\section{Deep-Hole Drilling Model}

The deep-hole drilling is a semi-destructive method of measuring residual stress distribution in an engineering component. The technique can be simulated in ABAQUS using finite element analysis involving several steps of material removal.

\section{Forged block}

Figure 1(b) shows the model mesh of the forged block. A quarter model was meshed with 52,800 eight-noded reduced integration linear brick elements. Figure 1(c) shows a schematic of the deep-hole drilling quarter model illustrating clearly the drilling and trepanning steps represented by $\mathrm{d} 1, \mathrm{~d} 2, \mathrm{~d} 3$ and $\mathrm{t} 1, \mathrm{t} 2, \mathrm{t} 3$ up to total step of 20. The regions (element sets) defining the drilling steps $(\mathrm{d} 1, \mathrm{~d} 2, \ldots \mathrm{d} 20)$ were removed in 20 successive steps followed by the subsequent removal of regions (element sets) defining the trepanning steps ( $\mathrm{t} 1$, $\mathrm{t} 2, \ldots \mathrm{t} 20)$ in 20 further steps. Drilling and trepanning were both carried out from one face (ST-LT) to the other along the longitudinal (L) axis of the forged block so that the ST-LT symmetry plane at $1 / 2 \mathrm{~L}$ does not exist and consequently only a quarter model was considered. In ABAQUS the element sets were removed in each step by using the "MODEL CHANGE REMOVE" keyword option in the input file [14]. The diametral distortions, at a number of angles through the axis of the forged block, at the end of drilling and trepanning steps, were used to determine the residual stress present in the specimen. Both the conventional and the improved optimised deep-hole drilling techniques were modelled and are briefly described in Section 4.1.

\section{Ring weld}

The deep-hole drilling finite element analysis (DHDFEA) simulation was carried out in three steps. First, the axisymmetric results were rotated through a $3 \mathrm{D}$ half disc as shown in Fig. 9(a-b). Second, the 3D stress and strain fields were mapped onto a 3D deep-hole drilling FEA model shown in Fig. 9(c). Third, the standard deep-hole drilling (DHD), the modified incremental deep-hole drilling (iDHD) and the modified over-coring deep-hole drilling (oDHD) simulations, as shown in Fig. 9(d), were carried out. Figure 9(c) also shows the model mesh used to perform the deep-hole drilling simulations. The mesh in Fig. 9(e) and (f) illustrates the fine mesh used for the oDHD and the iDHD simulation respectively, where the details of the various trepanning diameters and the drilling region are clearly shown.

\section{Autogenously welded plate}

Figure 3(c) shows the model mesh of the autogenous bead on plate specimen. Due to symmetry in the $x-y$ plane, a half model with 4812 predominantly eightnoded reduced integration linear brick elements C3D8R was meshed. The overall geometry of this mesh is identical to that of the welded mesh in Fig. 3(b). This permits the mapping procedure in ABAQUS to map the original welding residual stress and strain fields from the welding model onto the DHD model. Figure 3(d) provides a close-up of Fig. 3(c) illustrating the drilling and the trepanning steps.

A brief outline of the basic principle of the DHD method - both the conventional and the improved optimised method is provided in the next section with relevance to the FEA model constructed to allow the DHD simulation and description of the additional boundary conditions. 
Fig. 9 Main steps (a)-(d) in the deep-hole drilling simulation. Details of the mesh (e), (f) for the deep-hole drilling simulation in the $3 \mathrm{D}$ model

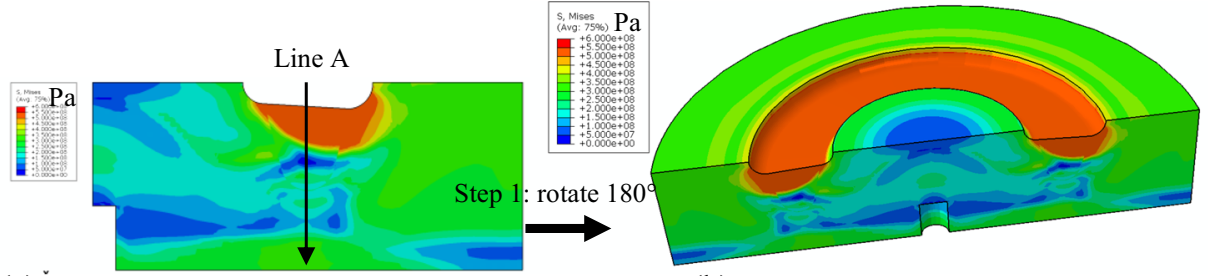

(a) 2D welding stress, distribution of effective stress

(b) Rotate axisymmetric results to 3D results

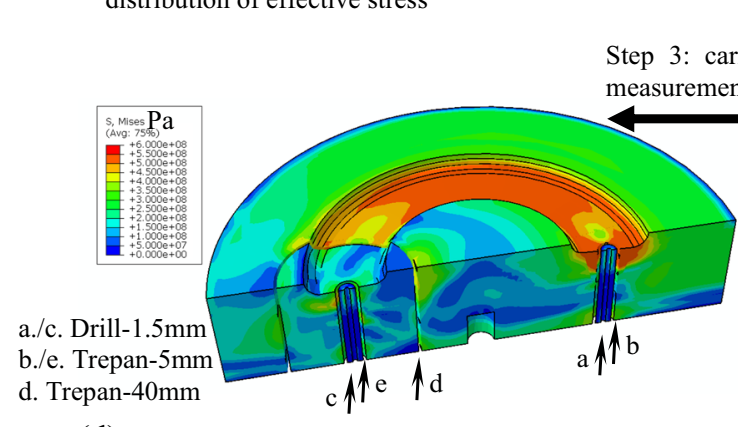

(d) Stress results at the end of DHD simulation

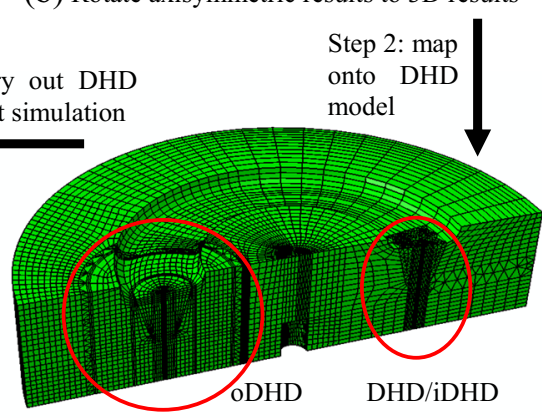

(c) 3D model of DHD simulation

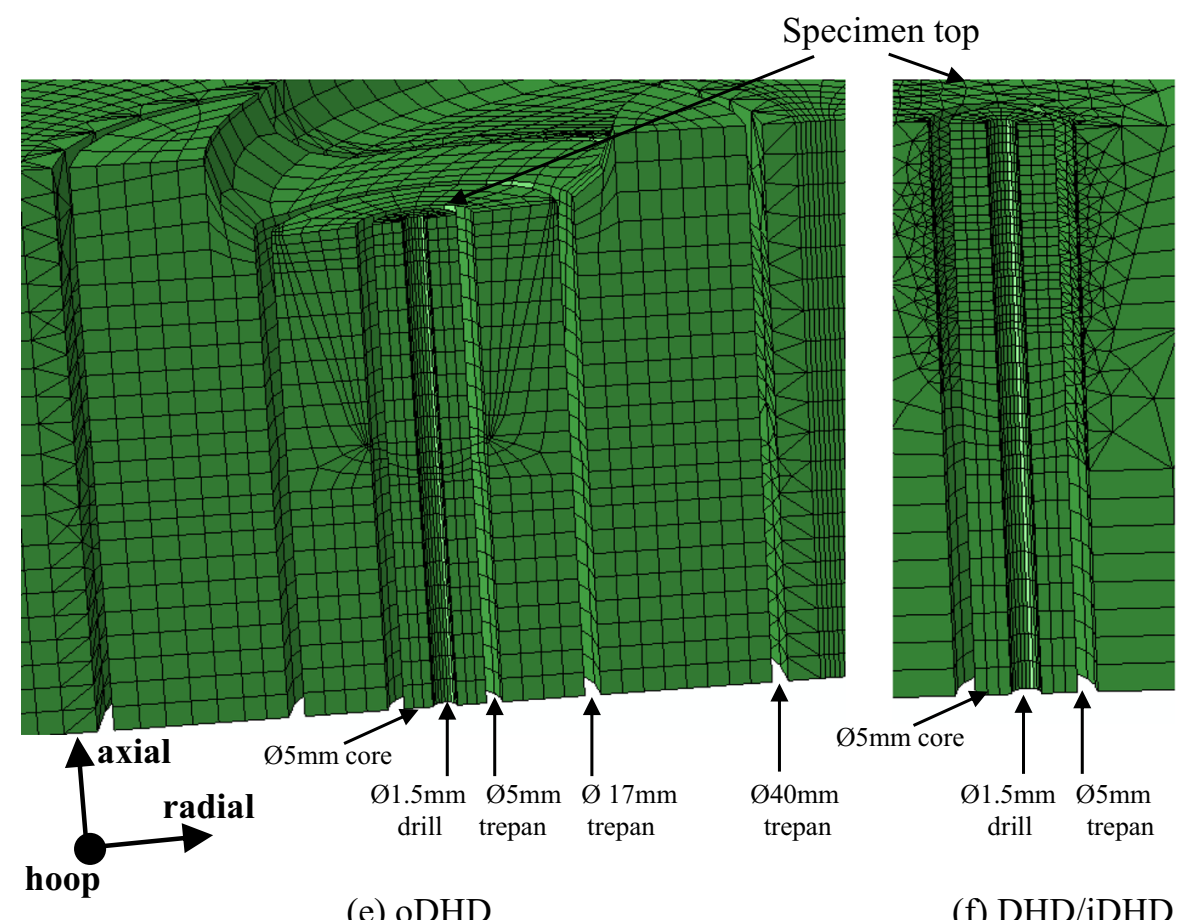

(e) oDHD

(f) $\mathrm{DHD} / \mathrm{iDHD}$

\section{Residual Stress Measurement Techniques}

Two residual stress measurement techniques were used to measure the residual stress fields in the quenched and welded samples. These included the deep-hole drilling technique (both the conventional and the improved modified deep-hole drilling technique), and the neutron diffraction technique.

\section{Deep-Hole Drilling Technique}

The deep-hole drilling method determines the throughthickness residual stress distribution in a component by measuring the change in diameter of a reference hole that occurs when a core of material is removed from the component by trepanning. A schematic illustration of the DHD method is shown in Fig. 10. Full details 

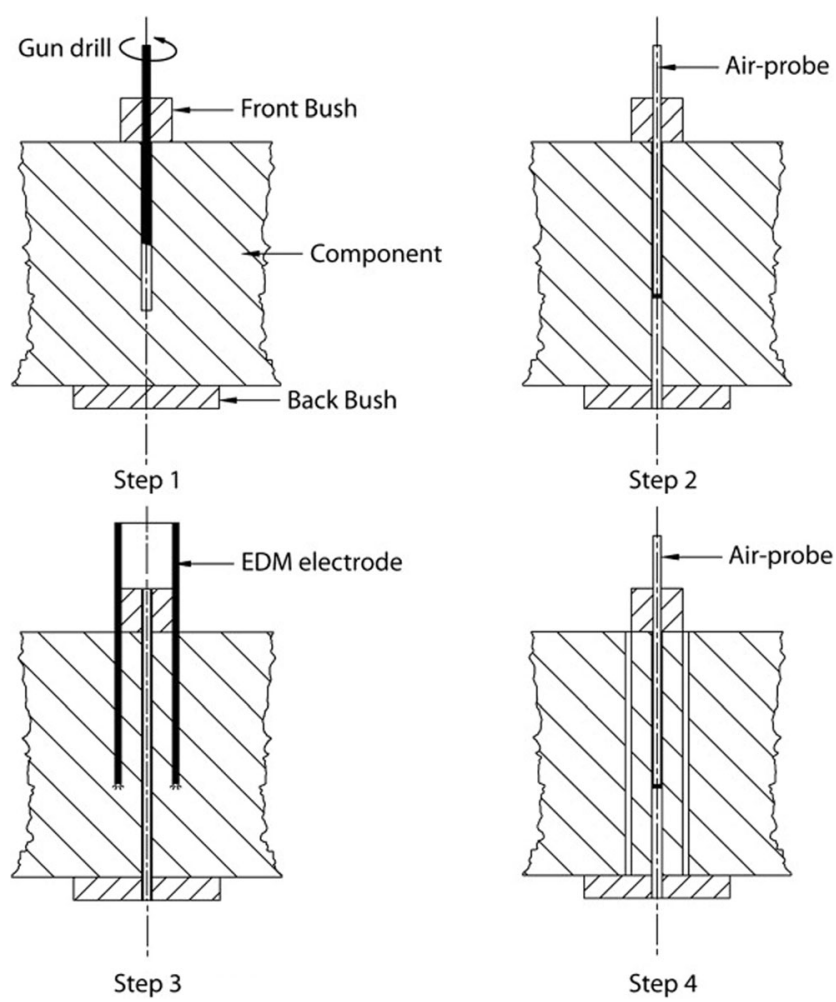

Fig. 10 A schematic illustration of the procedural steps in the deep-hole drilling technique: step 1 - drilling of reference hole, step 2 - measurement of reference hole diameter, step 3 - trepanning of core and step 4 - remeasurement of reference hole

of the method can be found elsewhere $[15,16]$. Only an outline of the procedure is included here. The steps 1-4 in the DHD method are as follows:

1. A reference through hole is gun-drilled through the component.

2. Accurate measurements of the initial reference hole diameter are taken at a number of angles around the reference hole axis $\theta$ and at several increments of depth $z$, giving $d(\theta, z)$.

3. A core of material containing the reference hole is trepanned free of the rest of the component using a plunge electric discharge machine. The trepanned cylindrical core is macroscopically "stress-free".

4. After core removal, the reference hole diameter is re-measured in the same manner as in step 2, giving $d^{\prime}(\theta, z)$.

The changes in diameter of the reference hole are used to calculate the in-plane distribution of the residual stress through the thickness of the component. Details are provided in Appendix.
Improved modified DHD technique

Two modifications to the standard deep-hole drilling technique were made in order to improve the conventional technique. The first included the incremental deep-hole drilling (iDHD) technique. Detail of this method is provided in [17], only the key features are summarised here, Section 4.2. The second method included the decreasing trepanning method, also known as the over-coring deep-hole drilling (oDHD) method and is described in Section 4.3.

\section{Incremental Deep-Hole Drilling}

The procedure is similar to that of the conventional DHD technique with modifications/additions made to steps 3 and 4 of Fig. 10. In step 3, the core is not completely trepanned free of the component. Instead the trepanning is partially carried out in a number of pre-set increments. At the end of each trepanning step, the reference hole diameter is re-measured. Thus, the diameter $d_{i}^{\prime}\left(\theta, z_{i}\right)$ at the end of each trepanning step to a depth $z_{i}$ is obtained. If $N$ is the number of trepanning steps, then $i=1,2 \ldots N$.

The change in reference hole diameter is calculated for each trepanning increment

$\delta d_{i}\left(\theta, z_{i}\right)=d^{\prime}{ }_{N}\left(\theta, z_{N}\right)-d^{\prime}{ }_{i}\left(\theta, z_{i}\right)$

The changes in reference hole diameter for each trepanning step are then converted into strain using

$\tilde{\varepsilon}_{i}\left(\theta, z_{i}\right)=\frac{\delta d_{i}\left(\theta, z_{i}\right)}{d^{\prime}{ }_{N}\left(\theta, z_{N}\right)}$

Using a pseudo-inverse matrix similar to the conventional DHD analysis the unknown stress components $\left\{\sigma_{i}\left(z_{i}\right)\right\}$ are calculated from the measured hole strains using least squares:

$\left\{\sigma_{i}\left(z_{i}\right)\right\}=-\left\{\left[M\left(z_{i}\right)\right]^{T}\left[M\left(z_{i}\right)\right]\right\}^{-1}\left[M\left(z_{i}\right)\right]^{T}\left\{\tilde{\varepsilon}_{i}\left(z_{i}\right)\right\}$

This method is applied to all the specimens including the quenched forged block (Fig. 1), the ring weld (Figs. 2 and 9) and the autogenously welded plate specimen (Fig. 3). Note that while in the conventional DHD a high spatial resolution in the residual stress distributions (usually every $0.2 \mathrm{~mm}$ ) is obtained, the spatial resolution in the incremental deep-hole drilling method is limited to the number of pre-set trepanning steps, normally ranging between 10 and 20 steps.

\section{Over-Coring Method}

The decreasing trepanning or the over-coring deep-hole drilling (oDHD) method in principle is similar to the conventional DHD method with additional steps of trepanning a core with 
larger diameter. This method is also simulated for the ring weld, Fig. 9 and the autogenously welded plate, Fig. 3. Following the drilling step (diameter of $1.5 \mathrm{~mm}$ ), a large core of diameter $40 \mathrm{~mm}$ is first trepanned followed by a medium core of diameter $10 \mathrm{~mm}$ and finally the usual $5 \mathrm{~mm}$ diameter core is trepanned. The advantages of this method over the incremental DHD method are (i) the spatial resolution as in the conventional DHD technique is retained and (ii) since the hole diameters at the end of drilling and at the end of final trepanning ( $5 \mathrm{~mm}$ core diameter) are only used in the usual DHD analysis the method is simpler and less time-consuming and thus more economical. The hole diameters following drilling step and at the end of final trepanning are treated exactly the same way as in the conventional DHD technique to determine the unknown residual stress components $\left\{\sigma\left(z_{i}\right)\right\}$.

\section{Neutron Diffraction Technique}

The application of neutron diffraction provides internal residual stress measurement in engineering components non-destructively. Strain components are directly measured from changes in lattice spacing of crystals when a beam of neutrons is incident on the component. It may easily be shown that if $2 \theta$ is the angle between the incident beam and the diffracted beam (Fig. 11) then with a polycrystalline sample constructive interference (and a subsequent peak in intensity) occurs when Bragg's law is satisfied

$2 d^{h k l} \sin \theta=\lambda$

where $d_{h k l}$ is the interplanar distance between planes of Miller indices $(h k l)$. Further details are provided elsewhere [18].

A stress-free lattice spacing $d_{0}^{h k l}$ must also be measured to measure absolute values of residual elastic strain. This permits using eq. (4) the strain component $\varepsilon_{i}$ in a direction defined by

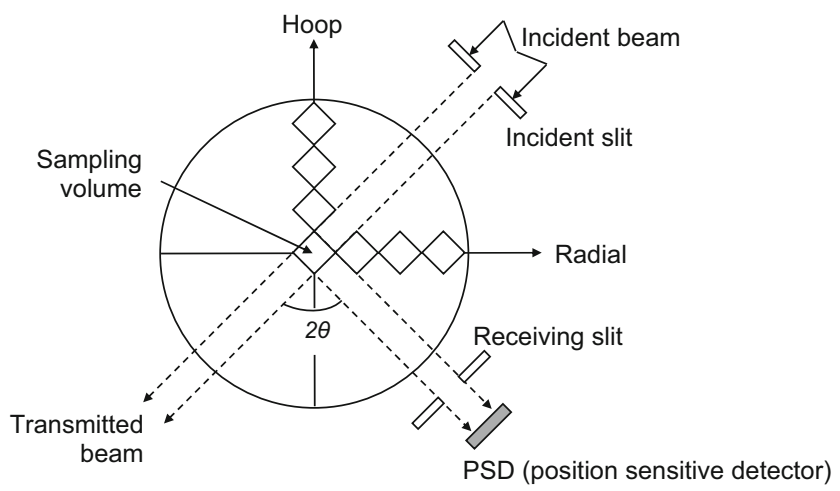

Fig. 11 Schematic layout of a neutron diffractometer the geometry of the incident and diffracted beam to be determined as

$\varepsilon_{i}=\frac{d_{i}^{h k l}-d_{0}^{h k l}}{d_{0}^{h k l}}=\frac{\Delta \lambda}{\lambda}-\cot \theta \Delta \theta$

For constant wavelength strain scanners, $\Delta \lambda=0$ and $\varepsilon_{i}=-\cot \theta \Delta \theta$, and for pulsed beam instruments, $\Delta \theta=0$ and $\varepsilon_{i}=\Delta \lambda / \lambda=\Delta t / t$. Residual stresses may then be determined from the measured residual strain components using Hooke's law.

$\sigma_{x x}=\frac{E}{(1+\nu)(1-2 \nu)}\left[(1-\nu) \varepsilon_{x x}+\nu\left(\varepsilon_{y y}+\varepsilon_{z z}\right)\right]$

where $E$ is the Young's modulus and $\nu$ is the Poisson ratio of the material. Similar expressions hold for the $y$ - and $z$ directions.

\section{Results}

This section describes the residual stress results including both the finite element predicted and the measured, accompanied with a brief discussion. First, results for the quenched forged block are provided, followed by the ring weld and finally results for the autogenously welded plate are presented and discussed.

\section{Quenched Forged Block}

Figure 12 shows the FEA predicted residual stress distributions along the longitudinal axis $\mathrm{L}$ of the quenched forged block showing (i) the initial quenching residual stress, (ii) the conventional DHD reconstructed residual stress and (iii)

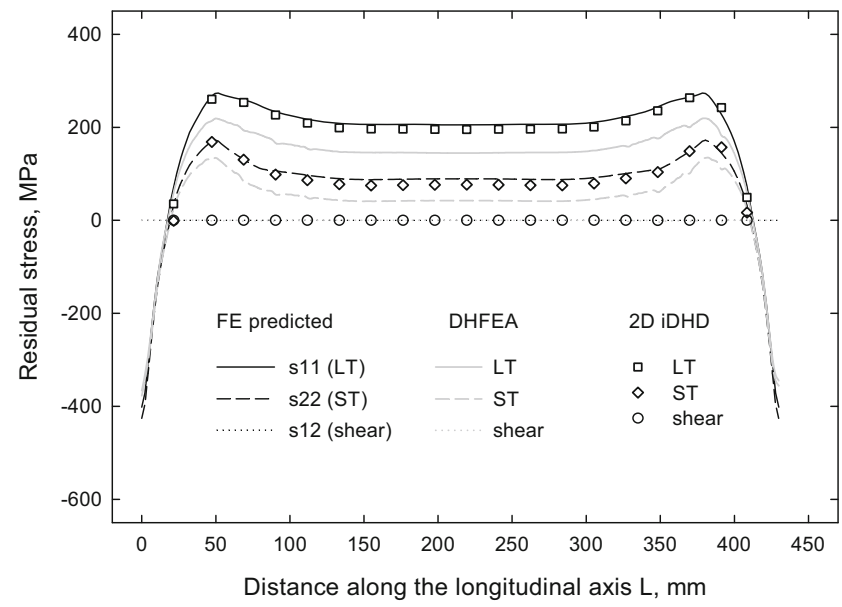

Fig. 12 FEA predicted residual stress distributions along the longitudinal axis $\mathrm{L}$ of the quenched forged block showing (i) the initial quenching residual stress, (ii) the conventional DHD reconstructed residual stress and (iii) the incremental iDHD reconstructed residual stress 
the incremental DHD (iDHD) reconstructed residual stress distributions. The longitudinal residual stress component is not shown as the drilling path here is along the longitudinal axis $\mathrm{L}$ and this component is not usually determined in the conventional DHD technique. As expected, the quenching residual stresses are equi-biaxial compressive on the outer surface and become tensile towards the inner core with LT component higher than the ST component. The level of the tensile LT residual stress component is close to the yield stress (see Fig. 5) so that care should be taken while using the deephole drilling technique. The effect of plastic distribution is clearly shown by the DHFEA (i.e. the DHD measurement simulation) result in Fig. 12. By utilising the improved method such as the incremental DHD method, the iDHD reconstructed residual stresses match very closely with the initial FEA predicted quenching residual stresses.

Figure 13 shows the measured LT and ST residual stress components along the longitudinal axis $\mathrm{L}$ of the quenched forged block [4]. Measurements using both the stress instruments ENGIN-X (time-of-flight method) at ISIS and SALSA (diffraction method) at ILL are shown. The level of stresses measured using the SALSA stress instrument is lower than that using the ENGIN-X stress instrument. For the same sample two different residual stress distributions are obtained. Two possible explanations for the discrepancy include (i) the effect of stressfree $\left(d_{0}\right)$ reference sample; a cube extracted from the corner of the block was used as the reference sample and was unable to account for any microstructural variation [19] and (ii) natural ageing of the specimen at room temperature; the measurement using the SALSA instrument was at a later date.

Figure 14 compares the ENGIN-X measured residual stress distributions with corresponding initial FEA predicted. A very

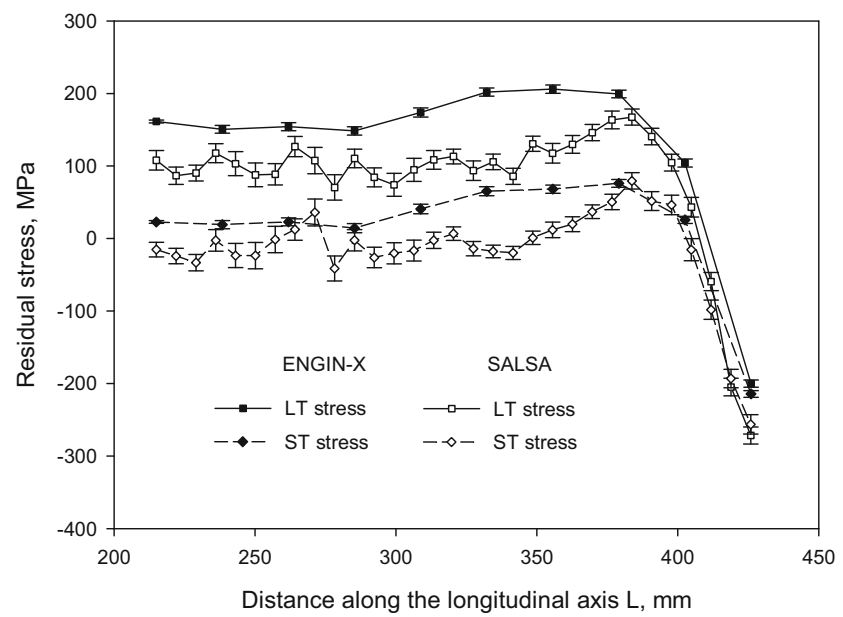

Fig. 13 ND measured residual stress distributions along the longitudinal axis L of the quenched forged block using both the ENGIN-X and SALSA stress instruments

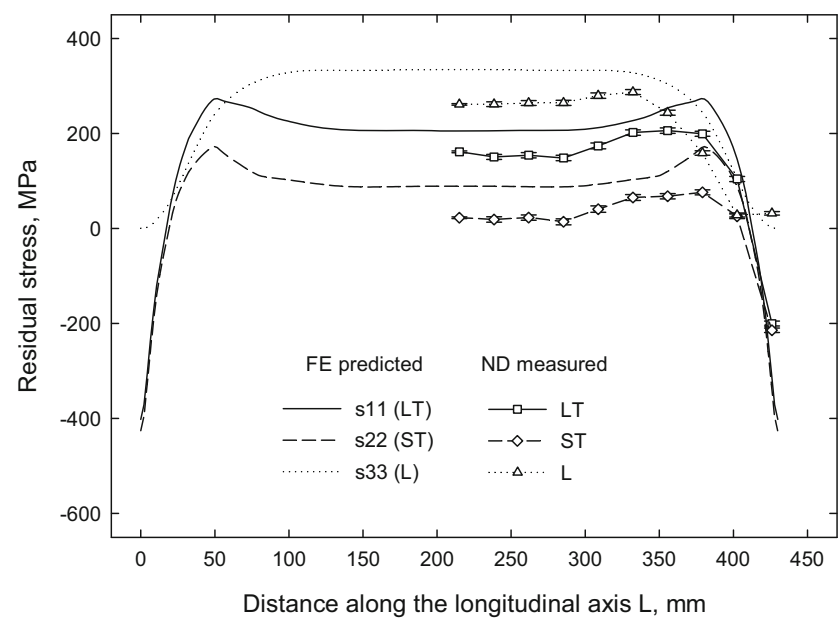

Fig. 14 Comparison of ENGIN-X measured with FE predicted residual stress distributions along the longitudinal axis $\mathrm{L}$ of the quenched forged block

similar trend exists but with a constant offset of approximately $55 \mathrm{MPa}$. This constant offset might arise from inaccurate $d_{0}$ stress-free measurement. In Fig. 15 after increasing the measured stresses by $55 \mathrm{MPa}$ the correlation improved considerably. Therefore the selection of a stress-free $d_{0}$ sample is critical in obtaining a reliable residual stress result using the neutron diffraction technique. Robinson et al. [19] by re-analysing stress-free $d_{0}$ sample obtained a higher ND measured residual stresses which correlated better with their FEA predictions.

Figures 16 and 17 show respectively a comparison of $L$ and LT residual stress distributions measured using different techniques including the ND technique, the conventional DHD technique and the incremental DHD technique. Here the stresses measured are along the short-transverse ST direction. The effect of the plastic distribution in the DHD technique is

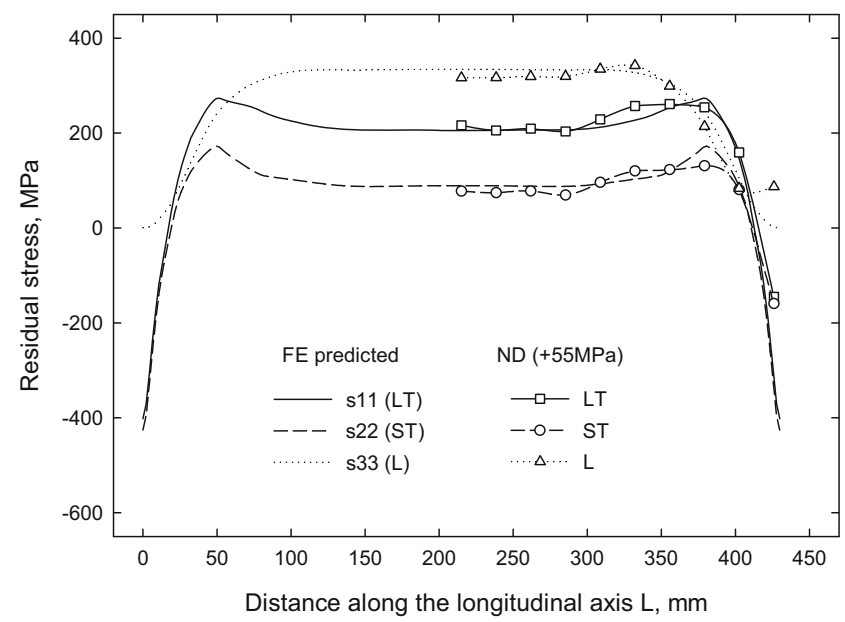

Fig. 15 Comparison of adjusted ENGIN-X measured with FE predicted residual stress distributions along the longitudinal axis $\mathrm{L}$ of the quenched forged block 


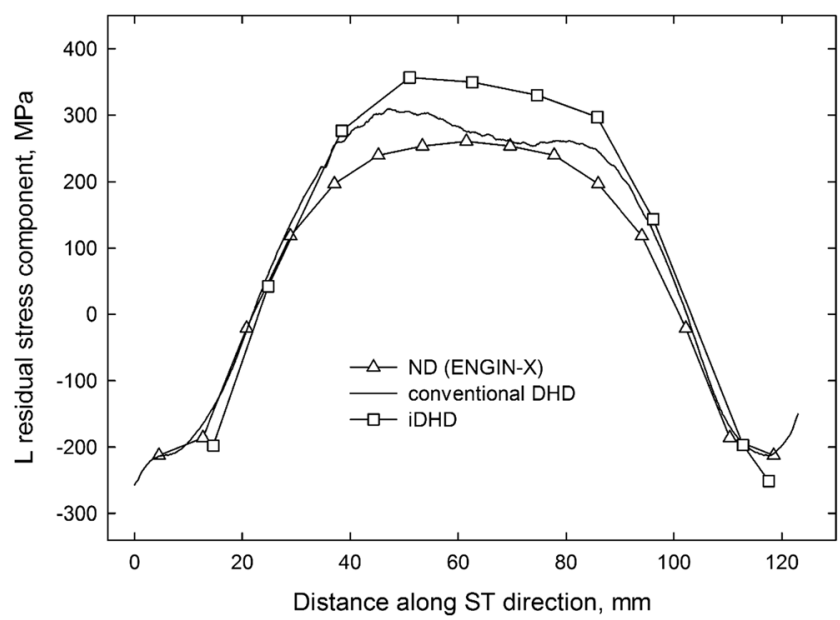

Fig. 16 Comparison of measured longitudinal (L) residual stress components using the neutron diffraction, the conventional DHD and the incremental DHD methods

clearly shown. The iDHD technique measured a higher residual stress distribution than the conventional DHD in much the same way as shown by the FE simulation results in Fig. 12. As expected the L component is greater than the LT component. Furthermore, both the iDHD and the conventional DHD measurements show that the stresses are not symmetric about the ST direction. Clearly quenching such a big block would make it difficult for symmetric heat transfer in practice. Therefore, in the neutron diffraction measurement or any other techniques it would be wrong to assume symmetry. Rather measurements should be carried out along the complete path surface-tosurface as is commonly done using the deep-hole-drilling technique. Secondly, by using a stress-free sample cut out completely through the measurement path, e.g., using a DHD core is likely to further improve the ND stress results.

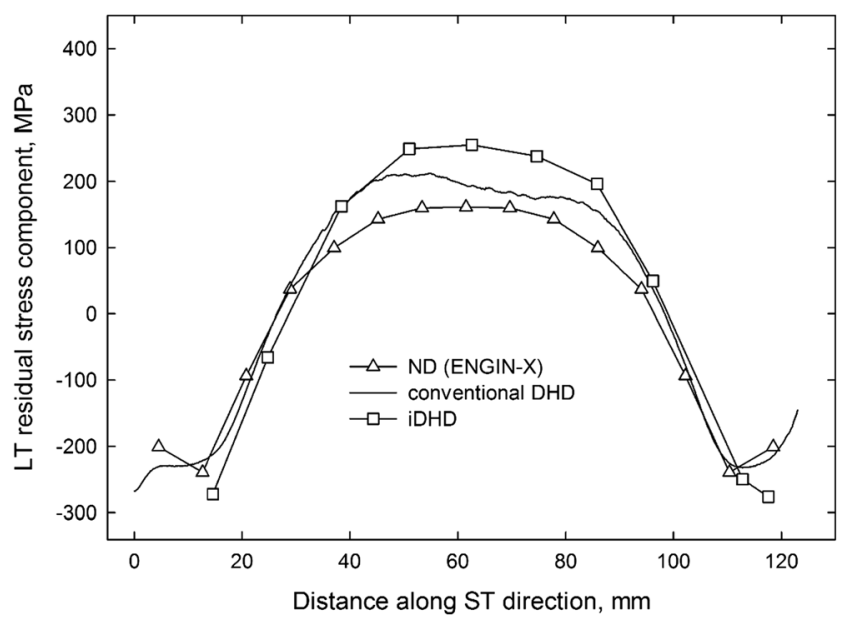

Fig. 17 Comparison of measured long-transverse (LT) residual stress components using the neutron diffraction, the conventional DHD and the incremental DHD techniques
Overall, both the FEA predicted results in Fig. 12 and the measurements in Figs. 16 and 17 show that the DHD redistribution is not as significant as was for a similar quenching process on a cylindrical solid specimen of dimension $60 \mathrm{~mm}$ diameter, $60 \mathrm{~mm}$ length reported elsewhere [20, 21], where the reconstructed residual stresses under the conventional technique broke down completely. One suggestion may be the effect of the size of the specimens involved. Since the dimensions of the drilling and trepanning remain the same for both cases, the drilling/trepanning to overall dimension changes significantly. In order to verify this effect, the DHD simulation on the large forged block was repeated but using a typical stainless steel material data. The results are shown in Fig. 18. The reconstructed DHD FEA residual stresses break away from the original predicted quenched residual stresses considerably. The only variable parameter here is the material property, namely the Young's modulus $E$. This is about three times higher in steel than in aluminium. Therefore, the possible explanation for the significant breakdown of reconstructed residual stresses in steel is that during trepanning the elastic unloading occurs at three times the gradient as compared to aluminium. Much of the plastic strain remains in the core for the steel case which does not readily relax as for aluminium.

\section{Ring Weld}

Neutron diffraction was conducted on the ring weld specimen to validate the FEA predicted weld residual stress. The instrument used to carry out the neutron diffraction measurements included the dedicated SALSA at the Institut Laure Langevin (ILL), Grenoble France. Details of this instrument are described in $[22,23]$. The neutron wavelength and the nominal Bragg angle were $1.648 \AA$ and $98.8^{\circ}$ respectively. The

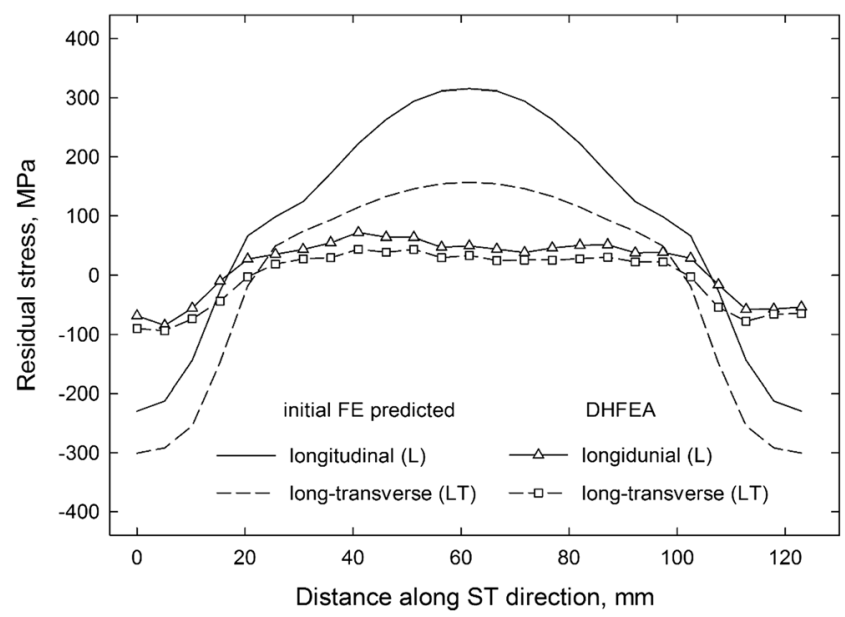

Fig. 18 Comparison of FE predicted quenched residual stress with conventional DHD reconstructed residual stress for the same block using stainless steel material data 
diffraction peaks corresponded to the $\{311\}$ lattice plane of austenitic steel with face-centred cubic (f.c.c.) structure. One comb sample used as the stress-free reference sample was extracted through the ring weld thickness to provide the $d_{0}$ stress-free measurement. This comb sample included a number of teeth. In order to achieve a high level of stress relief but at the same time simultaneously ensuring a completely filled gauge volume, the reference sample cross section was limited to $5 \mathrm{~mm} \times 6 \mathrm{~mm}$. Slots cut into the stress free sample created 8 teeth on the stress-free comb and permitted the axial stresses (i.e. the through-thickness stress component) to be completely relaxed. The comb sample provided stress-free diffraction data as a function of the distance across the thickness, accounting for microstructure and micro-stresses.

Neutron diffraction was conducted at $270^{\circ}$ position of the ring weld specimen. It had $12 \mathrm{ND}$ measurement points through the weld until reaching the parent metal. This measurement was conducted to measure the peak stress values in the welded and transition region. The ND measured residual stresses are shown in Fig. 19 and com-pared with the welding
Fig. 19 Comparison of measured residual stresses by the ND technique at $270^{\circ}$ position with the welding simulation

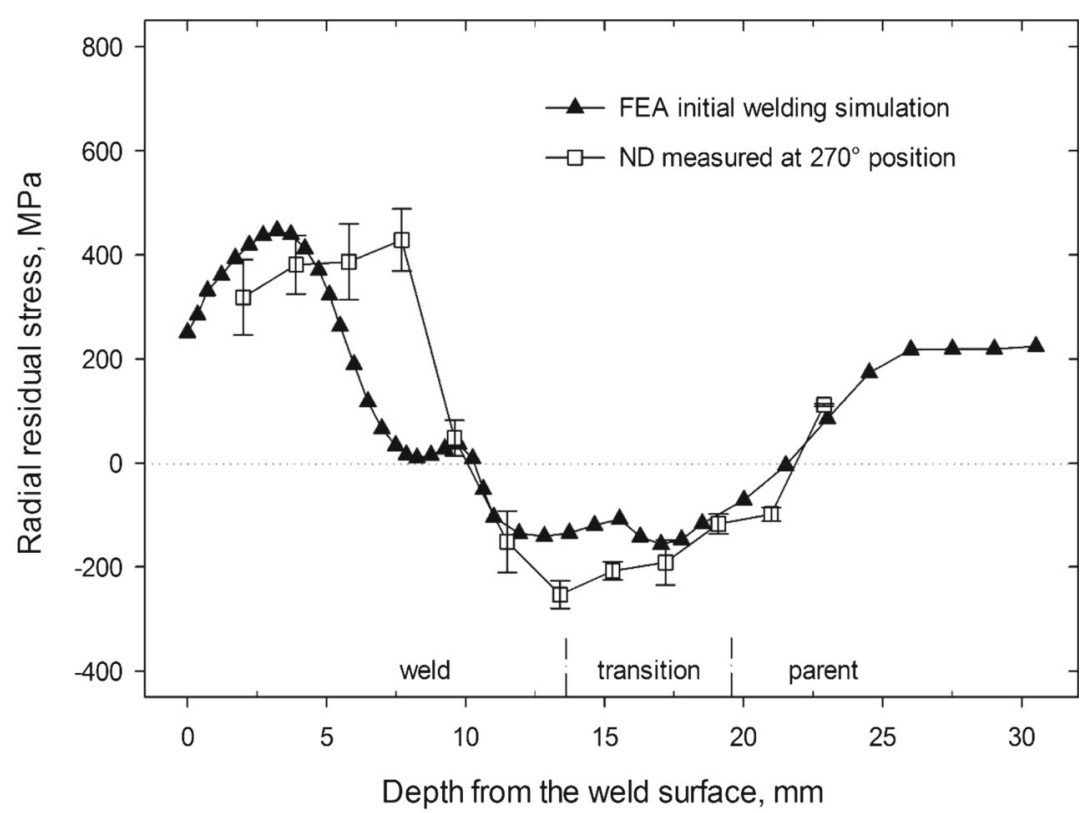

(a) Radial residual stress

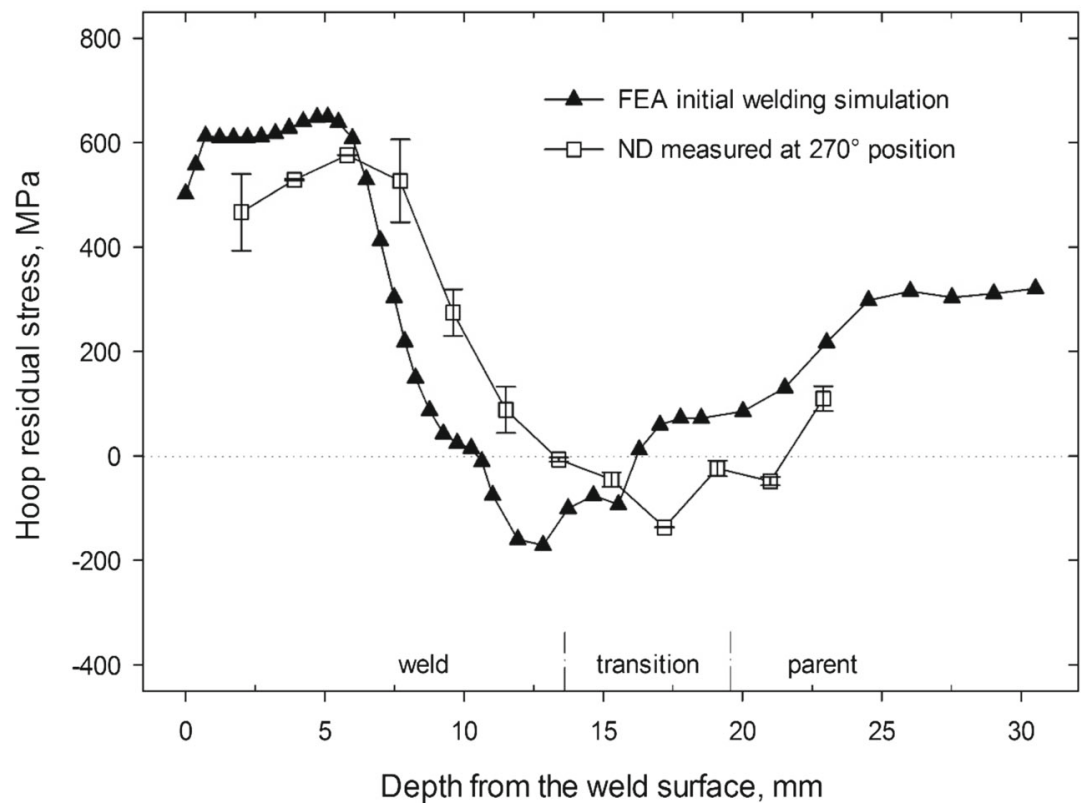

(b) Hoop residual stress 
simulation result. Overall an excellent correlation exists, in particular a very similar trend exists. Some differences between the ND measured and the FEA predicted results present can be thought to be due to the start/stop effect. The start/stop effect of the weld was not considered in the present FEA study and instead an axisymmetric model was considered. The ND measured results represent the stresses over a gauge volume (usually $1.5 \mathrm{~mm} \times 1.5 \mathrm{~mm} \times 1.5 \mathrm{~mm}$ ). The measured residual stresses would therefore not match $100 \%$ with the simulation. Nevertheless, in the present study which focusses on the optimisation of the DHD technique the comparison shown in
Fig. 19 is sufficient for further investigation on the measurement simulation.

The results from the simulations of the standard DHD, the incremental iDHD and the over-coring oDHD measurement processes through the weld centre line are shown in Fig. 20. Also shown are the initial weld residual stress components. The three simulations considered include DH1: the standard DHD, DH2: the iDHD, and DH3: the oDHD. For both the radial and the hoop directions, high tensile residual stresses were present at the top of the weld and decreased sharply to compressive stresses around the weld/parent interface
Fig. 20 Comparison of initial residual stress distributions with standard DHD (DH1), iDHD (DH2) and oDHD (DH3) measurement simulations

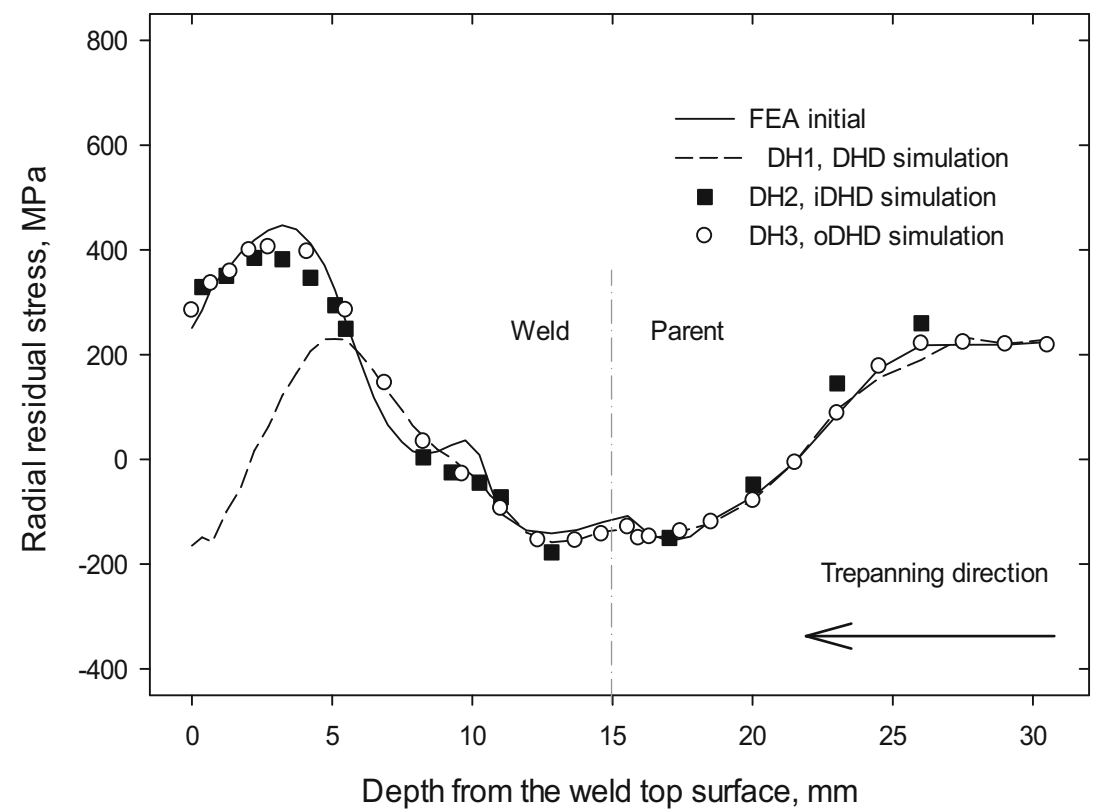

(a) Radial stress

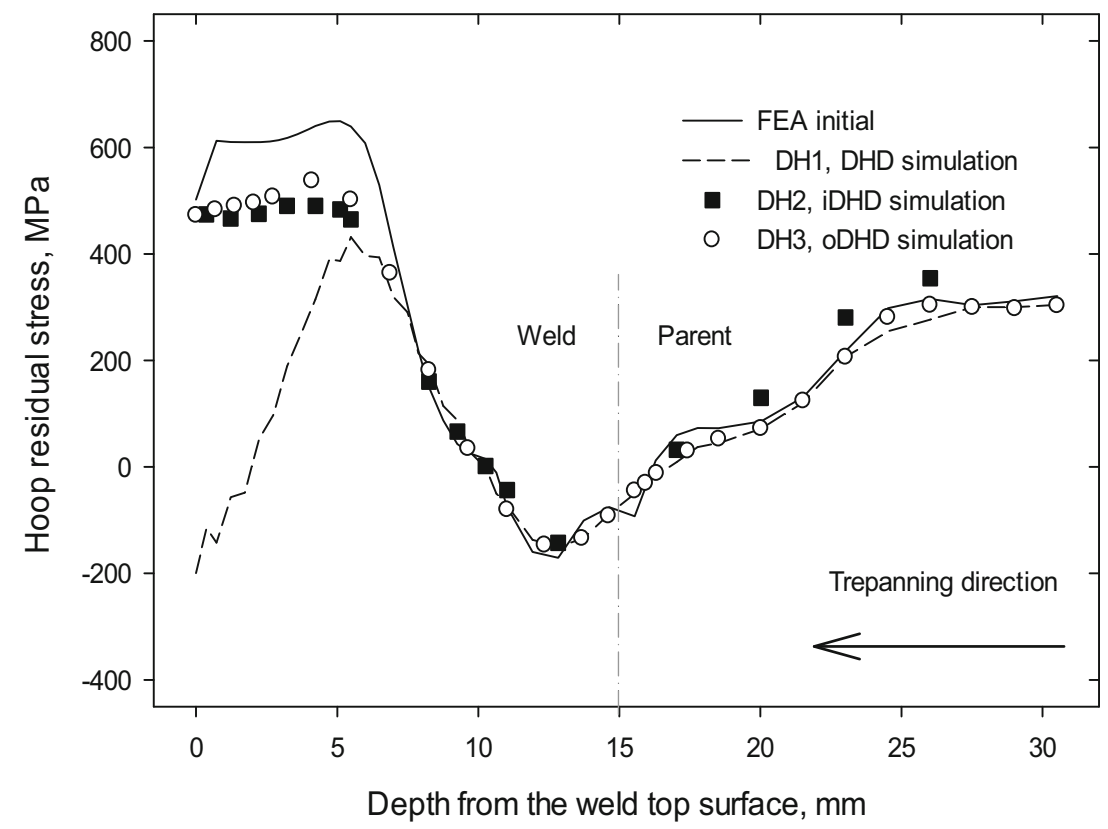

(b) Hoop stress 
$(15 \mathrm{~mm})$ followed by tensile residual stresses again. In the weld top region, the hoop stress reached a magnitude of $650 \mathrm{MPa}$ while the radial stress reached $450 \mathrm{MPa}$.

The trepanning simulation was carried out starting from the parent side and moving towards the weld top. The standard DHD simulation initially 'measured' both the radial and the hoop residual stresses correctly for the parent side, but when the high tensile weld region was reached near the weld top the simulated 'measured' tensile stresses remained relatively low. The presence of high residual stress near and above the yield stress caused plastic deformation during the trepanning procedure. This is the main reason why the standard DHD does not reconstruct near high yield tensile residual stresses.

The iDHD simulation which accounts for plasticity and the oDHD simulation which avoids plasticity both reconstructed well the residual stresses and is shown as solid squares and open circles respectively in Fig. 20. The iDHD and the oDHD radial stresses matched well with the initial FEA stress at all locations through the weld centre. For hoop stresses, the iDHD and the oDHD methods provided results which were in better agreement than the standard DHD but still did not completely reconstruct the residual stresses in the welded region. There are several possible reasons for this difference. First, this analysis did not account for the out-of-plane through thickness stress component, the axial stress component. Secondly, the iDHD/oDHD procedures may cause additional plastic deformation during drilling or trepanning procedures.

\section{Autogenously Welded Bead-on-Plate Results}

The thermal residual stress and strain fields predicted for the autogenously welded bead-on-plate model (Fig. 3(b)) described in Section 3.2 was mapped using ABAQUS [14] on to a further model (Fig. 3(c)) which allowed the DHD simulation procedure. The mapping procedure using the FEA interpolation process is described briefly in [20,21]. Figure 21

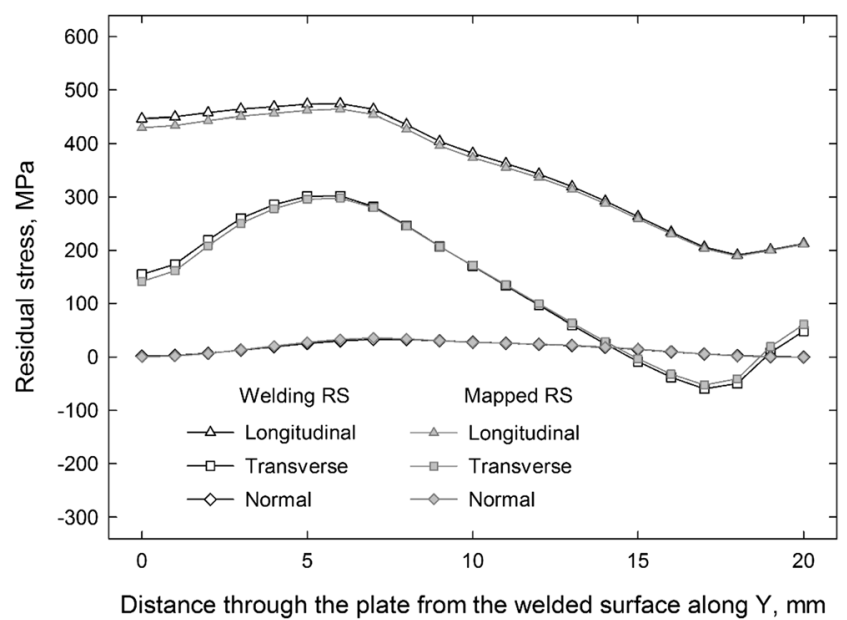

Fig. 21 Welded residual stress fields mapped on to DHD model

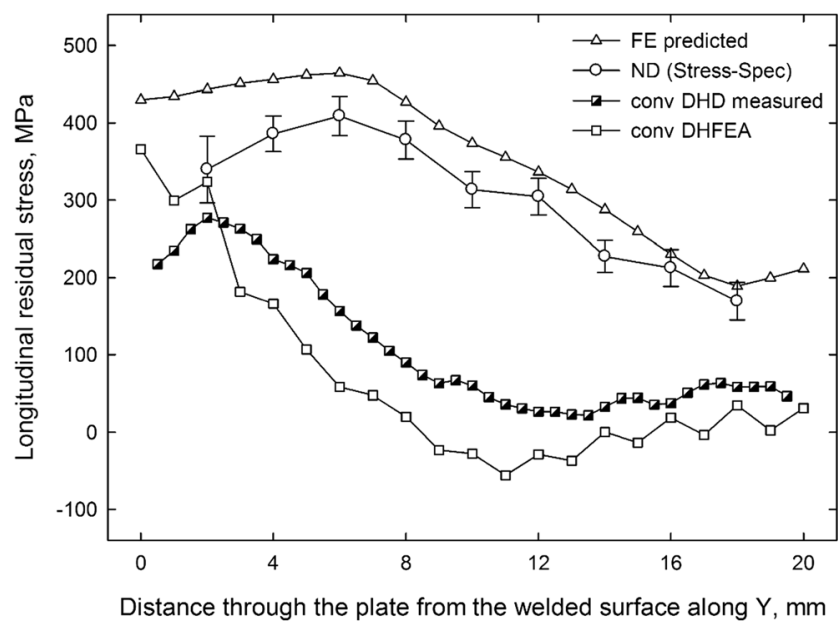

Fig. 22 Comparison of measured (ND and conventional DHD) and FE predicted (initial welded and conventional DHD simulation) longitudinal residual stress components

compares the initial welded residual stresses after mapping on to the DHD model. An excellent correlation illustrates successful mapping procedure. For results shown in Figs. 21, 22, 23, 24 and 25, the longitudinal component is along the welding direction (along the length of the bead-on-plate, i.e., along $X$ in Fig. 3(a)), the transverse component is transverse to the welding direction (along $\mathrm{Z}$ in Fig. 3(a)) and the normal component is along through-thickness of the bead-on-plate (along Y in Fig. 3(a)).

Figure 22 compares the longitudinal component of the initial FEA predicted weld residual stress distribution with the ND measured using the Stress-Spec stress instrument at FRM II and the conventional DHD measured residual stress distribution. Good correlation exists between the FEA predicted and the ND measured. In contrast, the comparison between

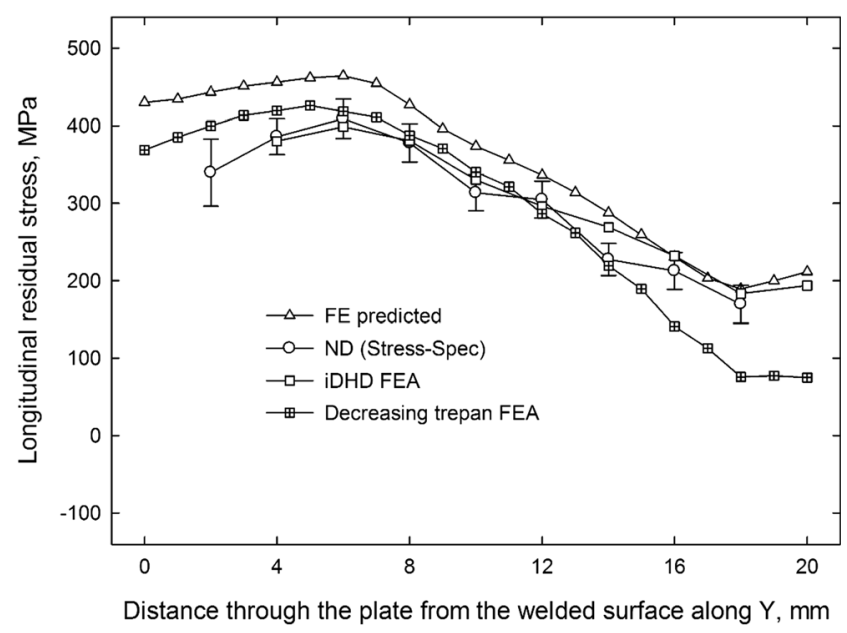

Fig. 23 Comparison of ND measured and FEA predicted initial welded, reconstructed $\mathrm{iDHD}$ and reconstructed oDHD (decreasing trepanning) longitudinal residual stress components 


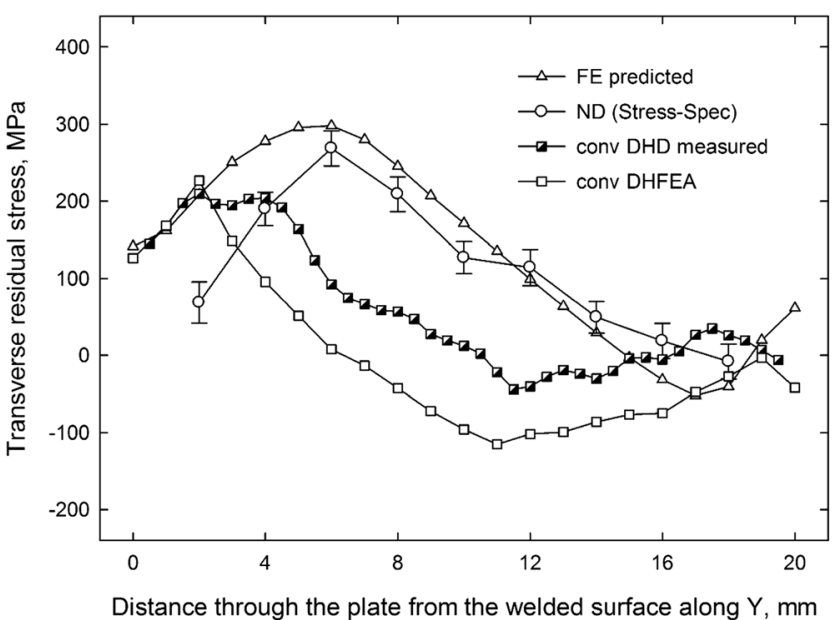

Fig. 24 Comparison of measured (ND and conventional DHD) and FEA predicted (initial welded and conventional DHD simulation) transverse residual stress components

the FEA prediction and the DHD measured is poor. Also shown in the figure is the reconstructed conventional DHD FEA simulation. The correlation between the reconstructed conventional DHD FEA simulation and the DHD measured is very good illustrating the influence of the DHD technique on the initial residual stress distribution. The standard DHD technique cannot be used to analyse the original welded residual stresses. By adopting the two modified techniques described in Sections 4.2 and 4.3 a significant improvement in reconstructed residual stresses is shown in Fig. 23. Both the incremental DHD (iDHD) and the decreasing trepanning results shown here are from FEA simulations and show an excellent correlation with both the initial FEA predicted and the ND measured weld residual stresses.

Results for the transverse component are shown in Figs. 24 and 25. Similar trend is obtained for the transverse component

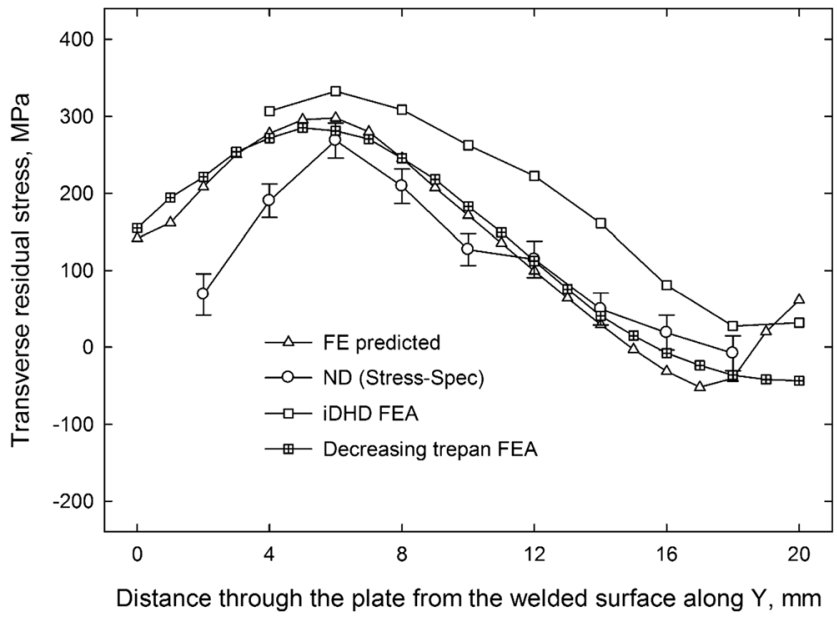

Fig. 25 Comparison of ND measured and FEA predicted (initial welded, iDHD and decreasing trepanning oDHD simulation) transverse residual stress components as for the longitudinal component. As shown in Fig. 24, the ND measured residual stress distribution compared very well with the initial FEA predicted weld residual stress distribution. The reconstructed residual stresses under the conventional DHD technique for both the FEA simulation and the measurement did not match with the initial distribution. The modified techniques including the iDHD and the decreasing trepanning improved the FEA reconstructed residual stress component as shown in Fig. 25. In particular, the reconstructed residual stress distribution using the decreasing trepanning method provided a better correlation which also provided a better depth resolution.

\section{Discussions}

The results presented in this paper illustrate the finite element analyses to be a valuable tool in not only predicting the initial residual stresses in an engineering component, but also a powerful tool in selecting an appropriate modification to the conventional deep-hole drilling method when the predicted stress level is close to the material yield stress. The same argument holds for other invasive residual stress measurement methods where material removal is required. It was shown that the value of Young's modulus $E$ played an important role in the breakdown of the standard DHD technique when measuring residual stress of high magnitude as shown by Fig. 18 .

Figure 13 shows significantly different residual stress profiles measured for the same specimen using two different stress instruments. This illustrated how critical the selection of an appropriate stress-free $d_{0}$ sample can be in the neutron diffraction residual stress measurements.

The ring weld results provided an example where the neutron measurements can be used to verify, optimise and fine tune the FEA predictions. In contrast, the forged block and the autogenously welded bead on plate sample illustrated how the use of finite element tool along with a number of available measurement techniques can help to optimise the final residual stresses.

The unknown residual stress components in an engineering component may be determined via one of the two routes, the finite element prediction or the residual stress measurement. The combination of the two, however, can increase the accuracy and the confidence in the end result. This is summarised and illustrated in Fig. 26 using a flow chart. The flow chart summarises the overall outcome of the results discussed in the present paper and provides a potential mechanism of how an optimisation of the residual stress characterisation can be achieved in practice. The following steps summarise the mechanism. 
Fig. 26 Summary of the optimisation steps in the residual stress characterisation

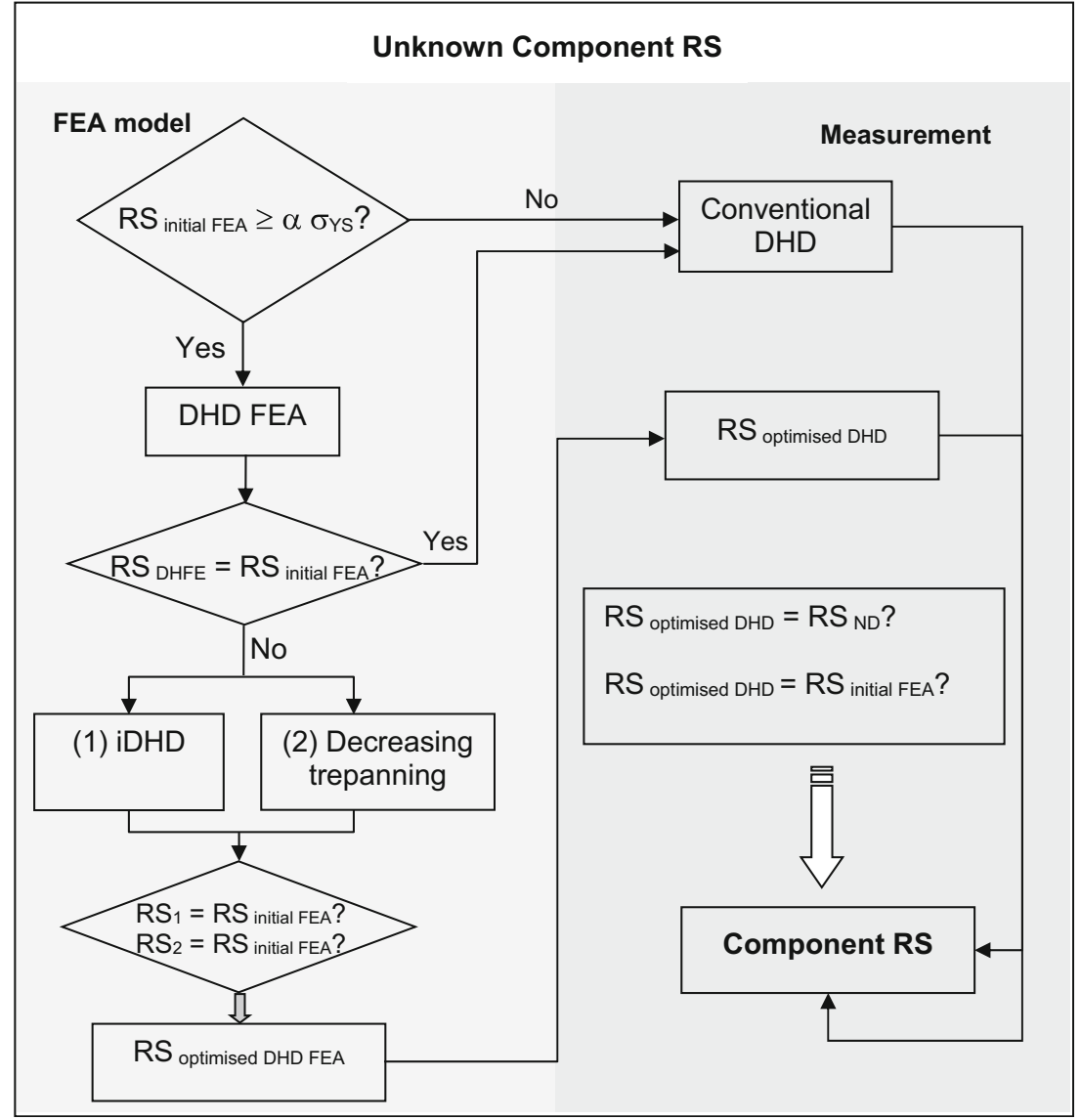

i. A finite element analysis of the process condition predicts the initial residual stress in the component, $\mathrm{RS}_{\text {initial FEA }}$

ii. If this stress level is less than $70 \%(\alpha=0.70)$ of the material yield stress then the conventional deep-hole drilling can be used to measure the residual stress which can in turn be used to validate the FEA prediction.

iii. However, if the stress level is more than $70 \%$ yield stress, a finite element simulation of the deep-hole drilling technique needs to be carried out to check whether the conventional DHD reconstructed residual stress, $\mathrm{RS}_{\text {DHFE }}$ approximately equals the initial predicted residual stress, RS initial FEA.

iv. If equal, then the conventional DHD can be used in practice to measure the residual stress.

v. If the reconstructed residual stress deviates significantly from the initial FEA predicted stress, two further improved DHD, i.e., (1) the incremental iDHD and (2) decreasing trepanning DHD are to be simulated.

vi. The improved DHD reconstructed residual stress is compared with the initial FEA predicted stress and the optimised FEA predicted residual stress can be achieved.

vii. The FEA simulation of the three different DHD methods thus help in optimising the DHD measured residual stress, RS optimised DHD.
viii.The optimised DHD measured residual stress can also be used to verify both the residual stress measured using the neutron diffraction technique and the FEA predicted initial residual stress.

ix. Finally an accurate residual stress state in the component can be achieved.

\section{Conclusions}

Three different samples including a quenched forged block, a ring welded short cylinder and an autogenously bead-on-plate were studied. Finite element analysis and different measurement techniques including the neutron diffraction technique and the deep-hole drilling techniques were used to characterise the residual stresses in the samples. The neutron diffraction measurements generally compared well with the initial FEA predicted residual stress components. This was particularly true for the quenched forged and the autogenously bead-onplate samples. Further tuning in the FEA model of the ring weld is required in order to achieve a better correlation with the neutron diffraction measured residual stress, in particular for the hoop component. 


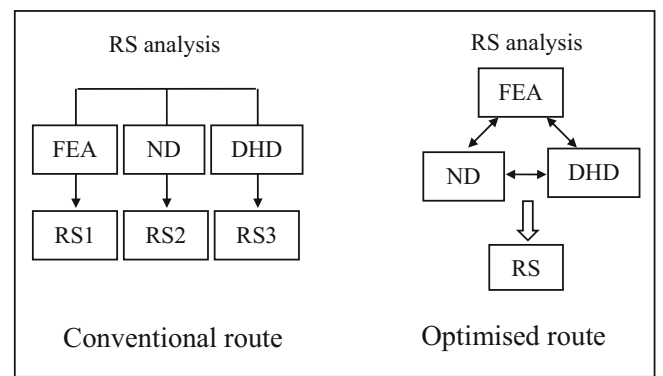

Fig. 27 Illustration of conventional and proposed optimised route in residual stress analysis

The conventional deep-hole drilling measurements in the forged block and the autogenously welded plate sample did not correlate with the initial FEA predicted stress. The DHD method did not work for the high residual stress level as was expected. The breakdown of the method was verified by conducting a DHD simulation in each case. The DHD simulation provided valuable guidance into selecting an optimised DHD method to measure the residual stresses correctly. The implication of the present findings points towards the establishment of a residual stress optimising tool as illustrated in Fig. 27, where the use of more than one available technique complementary to each other can be availed in order to accurately characterise the residual stress state in an engineering component, in particular where safety is critical.

Acknowledgements This investigation has been supported by the European Commission under the 6th Framework Programme project known as COMPACT (AST4-CT-2005-516078), which contributes to the thematic priority "Strengthening Competitiveness" of the European aircraft industry. The authors acknowledge the beam time and facilities provided by the Institut Laue Langevin, ISIS and FRM-II.

\section{Appendix: Deep-Hole Drilling Technique}

The experimentally measured changes in reference hole diameter are converted into strains by normalizing with the measured reference hole diameter before core removal. The change in the reference hole diameter is calculated according to

$\Delta d(\theta, z)=d^{\prime}(\theta, z)-d(\theta, z)$

where $d$ and $d$ ' are the reference hole diameters before and after trepanning respectively, which are each functions of the angular orientation around the hole, $\theta$, and the depth through the core thickness, $z$.

The changes in reference hole diameter are then converted to strains using

$\tilde{\varepsilon}(\theta, z)=\frac{\Delta d(\theta, z)}{d(\theta, z)}$
The reference hole strains are related to the residual stress components in the plane normal to the reference hole axis, $\sigma_{x x}(z), \sigma_{y y}(z)$ and $\sigma_{x y}(z)$, through a simple elastic analysis. The analysis is based on deformations occurring at a hole in a finite-thickness planar-infinite plate subjected to remote planar stress components assumed constant through the plate thickness. The reference hole strain that would occur for the given applied remote stress is given by

$\tilde{\varepsilon}(\theta, z)=\frac{f(\theta, z) \sigma_{x x}+g(\theta, z) \sigma_{y y}+h(\theta, z) \sigma_{x y}}{E}$

where the functions $f, g$ and $h$ were given by Garcia Granada et al. [24] as

$f(\theta, z)=A(z)[1+B(z) 2 \cos (2 \theta)]$

$g(\theta, z)=A(z)[1-B(z) 2 \cos (2 \theta)]$

$h(\theta, z)=4 A(z) B(z) \sin (2 \theta)$

where values of $A(z)$ and $B(z)$ are determined from FE analysis.

To find residual stresses that vary with depth, it is assumed that the trepanned core is composed of a stack of annular slices, which act independently of one another behaving in a manner predicted by the constant remote stress analysis.

A through-thickness residual stress distribution is calculated from measured reference hole strains through the use of a compliance matrix. Since the trepanned core is assumed to be composed of a stack of independent annular slices, stresses at a given depth are found independently from those at other depths. Reference hole strain is measured at a set of $\mathrm{n}$ depths $z=\left\{z_{1}, z_{2}, \ldots, z_{n}\right\}$ and a set of $\mathrm{m}$ angles $\theta=\left\{\theta_{1}, \theta_{2}, \ldots, \theta_{m}\right\}$, where $m \geq 3$. At each depth $z_{i}$, the measured strains are assembled into a vector of $m$ components

$\left\{\tilde{\varepsilon}\left(z_{i}\right)\right\}=\left[\tilde{\varepsilon}\left(\theta_{1}, z_{i}\right), \tilde{\varepsilon}\left(\theta_{2}, z_{i}\right), \ldots, \tilde{\varepsilon}\left(\theta_{m}, z_{i}\right)\right]^{T}$

The strain vector is then related to a vector of unknown stress components

$\left\{\sigma\left(z_{i}\right)\right\}=\left[\sigma_{x x}\left(z_{i}\right), \sigma_{y y}\left(z_{i}\right), \sigma_{x y}\left(z_{i}\right)\right]^{T}$

through

$\left\{\tilde{\varepsilon}\left(z_{i}\right)\right\}=-\left[M\left(z_{i}\right)\right]\left\{\sigma\left(z_{i}\right)\right\}$

where the elements of the matrix $\left[M\left(z_{i}\right)\right]$ are derived from eqs. (A3) to (A6) and are given by

$\left[M\left(z_{i}\right)\right]=\frac{1}{E}\left[\begin{array}{ccc}f\left(\theta_{1}, z_{i}\right) & g\left(\theta_{1}, z_{i}\right) & h\left(\theta_{1}, z_{i}\right) \\ \vdots & \vdots & \vdots \\ f\left(\theta_{m}, z_{i}\right) & g\left(\theta_{m}, z_{i}\right) & h\left(\theta_{m}, z_{i}\right)\end{array}\right]$ 
Finally, the unknown stress components $\left\{\sigma\left(z_{i}\right)\right\}$ are calculated from the measured reference hole strains using least squares:

$$
\left\{\sigma\left(z_{i}\right)\right\}=-\left\{\left[M\left(z_{i}\right)\right]^{T}\left[M\left(z_{i}\right)\right]\right\}^{-1}\left[M\left(z_{i}\right)\right]^{T}\left\{\tilde{\varepsilon}\left(z_{i}\right)\right\}
$$

Open Access This article is distributed under the terms of the Creative Commons Attribution 4.0 International License (http:// creativecommons.org/licenses/by/4.0/), which permits unrestricted use, distribution, and reproduction in any medium, provided you give appropriate credit to the original author(s) and the source, provide a link to the Creative Commons license, and indicate if changes were made.

\section{References}

1. Albertini G, Bruno G, Dunn BD, Fiori F, Reimers W, Wright JS (1997) Comparative neutron and X-ray residual stress measurements on Al-2219 welded plate. Mater Sci Eng A 224(1-2):157-165

2. (2005) Measurement of residual stress in materials using neutrons. IAEA-TECDOC-1457. IAEA, Vienna. ISBN 92-0-106305-9

3. Kingston E (2003) Advances in the deep-hole drilling technique for residual stress measurement. $\mathrm{PhD}$ Thesis, University of Bristol

4. Robinson JS, Hossain S, Truman CE, Oliver EC, Hughes DJ, Fox ME (2008) Influence of cold compression on the residual stresses in 7449 forgings. The Eighth International Conference on Residual Stresses, Denver, Colorado, USA

5. Alizadeh H, Lewis SJ, Gill C, Hossain S, Smith DJ, Truman CE (2008) Measurement and prediction of the residual stress field in an autogenously welded stainless steel plate. ASME PVP Conference, PVP2008-61341, Chicago, USA

6. Robinson J (2007) COMPACT deliverable report D2a.1.2, Measurement of the heat transfer coefficient during quenching of the aluminium alloy 7449

7. Smith MC, Smith AC (2006) NET bead on plate round robin: comparison of transient thermal prediction and measurements. Review. British Energy Generation Ltd, Barnwood

8. Dennis R, Leggatt N, Gregg A (2006) Optimisation of weld modelling techniques, bead-on-plate analysis. In: Proceedings of ASME PVP2006-ICPVT-11-93907

9. Zheng G (2013) Development of the deep-hole drilling method for residual stress measurement in metallic welds. PhD Thesis, University of Bristol, UK
10. Sen S, Aksakal B, Ozel A (2000) Transient and residual thermal stresses in quenched cylindrical bodies. Int J Mech Sci 42:20132029

11. Zheng G, Hossain S, Smith MC, Smith DJ (2014) Residual stress investigation in a stainless steel ring welded circular disc by overcoring deep hole drilling simulation and measurement. Proceedings of the ASME 2014 Pressure Vessels \& Piping Conference, Volume 6B: Materials and Fabrication

12. ABAQUS INC. (2005) ABAQUS/standard user's manual, 6.6 ed

13. Rosenthal D (1946) The theory of moving source of heat and its application to metal treatments. Trans ASME 68:849-866

14. ABAQUS INC. (2007) ABAQUS/standard user's manual, 6.7 ed

15. Kingston EJ, Stefanescu D, Mahmoudi AH, Truman CE, Smith DJ (2006) Novel applications of the deep-hole drilling technique for measuring through-thickness residual stress distributions. J ASTM Int 3(4): 1-12

16. George D, Kingston E, Smith DJ (2002) Measurement of through-thickness stresses using small holes. J Strain Anal 37(2):125-139

17. Mahmoudi AH, Hossain S, Truman CE, Smith DJ, Pavier MJ (2009) A new procedure to measure near yield residual stresses using the deep-hole drilling technique. J Exp Mech 49(4):595-604

18. Fitzpatrick ME, Lodini A (2003) Analysis of residual stress by diffraction using Neutron and Synchrotron radiation. Taylor \& francis, London

19. Robinson JS, Hossain S, Truman CE, Paradowska AM, Hughes DJ, Wimpory RC, Fox ME (2010) Residual stress in 7449 aluminium alloy forgings. Mater Sci Eng A 527:2603-2612

20. Hossain S (2005) Residual stresses under conditions of high triaxiality, $\mathrm{PhD}$ Thesis, University of Bristol

21. Hossain S, Goudar DM, Truman CE, Smith DJ (2011) Simulation and measurement of residual stresses in a type $316 \mathrm{H}$ stainless steel offset repair in a pipe girth weld. Mater Sci Forum 681:492-497

22. Pirling T, Bruno G, Withers PJ (2006) SALSA - a new instrument for strain imaging in engineering materials and components. Mater Sci Eng A 437(1):139-144

23. Hughes DJ, Bruno G, Pirling T, Withers PJ (2006) Scientific Review: First Impressions of SALSA: The New Engineering Instrument at ILL. Neutron News 17(3):28-320

24. Garcia Granada AA, George D, Smith DJ (1998) Assessment of distortions in the deep-hole technique for measuring residual stress. In: Proceedings of the 11 th Conference on Experimental Mechanics, Oxford, pp 1301-1306 